\title{
.MAMMALS FROM CHINA IN THE COLLECTIONS OF THE UNITED STATES NATIONAL MUSEUM
}

\author{
By A. Brazier Howell \\ Collaborator, United States National Museum
}

During recent years the attention of naturalists has been directed more and more to the fauna of Asia. The great variation in climate and topography have contributed in making this part of the earth's surface a region of extreme interest and the inaccessibility of a considerable portion of it has only stimulated our curiosity. That era in the history of Asiatic zoology when the majority of species obtained by an expedition proved to be new to science has largely passed, although novelties have by no means been exhausted. The time has come when an attempt should be made to sort and arrange what information we already have, to scrutinize the known species and establish their interrelationship, to correlate their ranges with what we know of faunal areas, and to bring as much order out of partial chaos as present circumstances permit.

The United States National Museum has accumulated from various sources a collection of Chinese mammals that is large and of extreme interest, and it seems eminently suitable that a report relating to it should be published at this time. The purpose of this may be said to be twofold: to present additional information concerning the mammals of regions that have been but imperfectly known; and to make available to students of Chinese mammalogy, who are not in ontact with large collections and libraries, some of the information which they may require.

The Chinese collections of the National Museum include adequate series of quantities of genera and species. Others, however, are represented by so few or such unsatisfactory specimens that in the absence of comparative material identification can at times be but provisional. In the case of the carnivores, especially, variation is frequently very great and new races in the greatest profusion as well as confusion have been described from very scanty material, often the flat pelt of a native hunter from no one knows exactly where. When such a condition is further complicated by a vague description, all one

No. 2772.-Proceedings U. S. National Museum, Vol. 75, Art. 1. $21776-29-1$ 
is able to do is to weigh facts and probabilities carefully and reach a personal conclusion which may or may not be correct. However, when the material has been unsatisfactory for proper identification in the present connection the fact is so stated.

The region included in the following report comprises the present Chinese Empire, including Mongolia, Manchuria, Korea, and the island of Hainan. There are listed a few specimens labelled eastern Tibet, which is permissible for the reason that at least until recent times, "eastern Tibet" was used in a very loose geographic sense, and as often as not included localities which are now within the Chinese provinces of Szechwan or Yunnan.

Upon initiating the present work it was determined to make a praiseworthy endeavor to reduce to a common plan of spelling the names of all Chinese localities mentioned, but this good intention was speedily abandoned. There are a number of different methods of changing the spelling of Chinese names to conform to our exotic ideas and one can never be sure which of these schemes was followed by the writer of a label or an article. Hence it is obvious that one can never be sure whether two slightly different names refer to the same spot or to separate places, perhaps not given on available maps. Clearly the only safe course at present, to avoid still greater confusion, is to list all names exactly as stated on the labels or in the literature, save in the case of well-known cities or provinces, when the spelling may be made uniform.

As a geographic basis I have used the atlas, 1917 edition, of the China Inland Mission, and when this failed me recourse was had to numerous other maps and atlases. Unfortunately there seems to be no good map of China which takes into adequate account the mountain ranges, and this fact renders extremely difficult a proper appreciation of the zonal barriers existing in such mountainous Provinces as Szechwan and Yunnan. Hence mistakes in the supposed ranges of such forms as these barriers affect are at times unavoidable.

The material upon which this report is based comprises 2,106 specimens of 283 species and subspecies, all of them belonging to the National Museum collections. These are mostly well-made skins with skulls, but there is also a considerable number of spirit specimens and a few skeletons. In addition there are sundry unlisted specimens which it was impossible to identify for one reason or another, such as odd skulls without locality, alcoholics of nestling rodents, etc. The listed specimens belong to 9 orders and 31 families as follows: 


\begin{tabular}{|c|c|c|c|}
\hline Mammalia & Forms & $\begin{array}{l}\text { Speci- } \\
\text { mens }\end{array}$ & Page \\
\hline Insectivora (total) & 27 & 105 & 5 \\
\hline Tupaiidae_._. & 2 & 5 & 5 \\
\hline Erinaceidae & 5 & 16 & 5 \\
\hline Talpidae_- & 7 & 16 & 7 \\
\hline Soricidae_. & 13 & 68 & 8 \\
\hline Chiroptera (total) & 35 & 353 & 11 \\
\hline Emballonuridae. & 1 & 9 & 11 \\
\hline Rhinolophidae_. & 4 & 71 & 11 \\
\hline Hipposideridae_ & 5 & 76 & 12 \\
\hline Vespertilionidae.. & 24 & 197 & 15 \\
\hline Carnivora (total) & 45 & 127 & 20 \\
\hline Ursidae_ & 5 & 9 & 20 \\
\hline Procyonidae & 1 & 2 & 23 \\
\hline Canidae....... & 6 & 10 & 23 \\
\hline Mustelidae_... & 18 & 68 & 24 \\
\hline Viverridae_.... & 6 & 19 & 30 \\
\hline Felidae ....... & 9 & 19 & 32 \\
\hline $\begin{array}{l}\text { Primates: Cercopithecidae } \\
\text { (total) }\end{array}$ & 5 & 19 & 34 \\
\hline Rodentia (total) - & 120 & 1,256 & 36 \\
\hline Sciuridae & 47 & 295 & 36 \\
\hline Muscardinidae. & 1 & 4 & 48 \\
\hline Cricetidae $\ldots . . . .$. & 26 & 277 & 48 \\
\hline Rhizomyidae . - & 2 & 8 & 54 \\
\hline Spalacidae .... & 4 & 41 & 54 \\
\hline Muridae _ . & 33 & 602 & 56 \\
\hline Zapodidae.... & 2 & 3 & 66 \\
\hline Dipodidae_.... & 4 & 25 & 66 \\
\hline Hystricidae...- & 1 & 1 & 68 \\
\hline Lagomorpha (total) & 20 & 103 & 68 \\
\hline Ochotonidae. & 12 & 56 & 68 \\
\hline Leporidae _. - & 8 & 47 & 71 \\
\hline Artiodactyla (total) & 28 & 132 & 73 \\
\hline Suidae _..... & 3 & 14 & 73 \\
\hline Cervidae. & 15 & 81 & 74 \\
\hline Bovidae_................. & 10 & 37 & 78 \\
\hline Edentata: Manidae (total) & 2 & 2 & 81 \\
\hline Cetacea: Odontoceti (total) $\ldots \ldots$ & 2 & 9 & 81 \\
\hline
\end{tabular}

Foremost in importance among these Chinese collections are the mammals secured by Arthur de C. Sowerby and donated to the Museum by Robert Stirling Clark. These number 1,319 items. They are mostly from the provinces of Shansi and Shensi, Chihli and Kansu, as well as many from Manchuria and Mongolia. Of great importance also is a collection of 440 specimens from south China, 
almost all of them from Fukien. Much of the early material taken by Mr. Sowerby and received nearly 20 years ago was identified by G. S. Miller, jr., not a few of them by means of comparisons which he made with types in the British Museum, but advances made in our knowledge of Chinese mammals since that time has necessitated the reworking of this material.

Next in numerical importance are 205 mammals collected by F. R. Wulsin on the National Geographic Society's Central China expedition and presented to the Museum by that organization. A number of provinces are represented among this material but of outstanding importance are his collections from Inner Mongolia and from the Minshan Mountains of southern Kansu-both regions of exceptional interest and otherwise unrepresented in the National collection.

Dr. David C. Graham, in the course of his missionary work, has taken occasion to collect under the auspices of the Museum 178 specimens of mammals, most of them being from the Province of Szechwan. It has been his fortune to secure more than a fair share of extremely rare species, and his efforts have been of exceeding value.

Dr. W. L. Abbott has presented to the Museum 186 mammals collected under his auspices by the late Charles M. Hoy. These are almost exclusively from the neighborhood of Yochow, Hunan, a district which is otherwise almost unrepresented in the National collection.

Also donated by the National Geographic Society is a collection of 61 mammals secured by J. F. Rock, mostly in Yunnan, which includes many rare squirrels as well as some desirable carnivores.

To the generosity of W. W. Simpson, who was engaged for some time in missionary work at Taochow, Kansu, the Museum is indebted for 38 mammals, mostly from Kansu, among which are such desirable items as gorals, stags, and an extremely rare bear.

Smaller but valuable collections have, in addition, been received as follows: From S. F. Light, 16 mammals from Hainan and the mainland adjacent; from C. B. Rickett, 12 mammals, mostly from Fukien; from A. P. Jacot, 7 mammals from Shantung; and from Canton Christian College museum, 5 mammals. This leaves 84 mammals from miscellaneous sources. These include specimens in the collection of C. Hart Merriam, material secured in exchange from many institutions, and the odds and ends that have accumulated throughout the years.

As a result of the present study, 18 species and subspecies have been described as new by the writer, and one by G. S. Miller. In addition, Miller, Lyon, Hollister, and Sowerby previously described 23 new forms based on this material, making a total of 42 new forms that have been described from the Chinese mammals now in the collection of the United States National Museum. 
Unfortunately Mr. Sowerby is the only one of the above collectors who kept field records of anything more than the actual specimens collected, and his notes regarding habits are only available for the collections which he made in Shansi, Shensi, and a part of Kansu. Many of these observations are included under their proper headings in this report. Others have been included in his books, among which are Through Shen-kan, 1912; Fur and Feathers in North China, 1914; A Sportsman's Miscellany, 1917; and Sport and Science on the Sino-Mongolian Frontier, 1918.

\section{Order INSECTIVORA}

\section{Family TUPAIIDAE}

\section{Genus TUPAIA Raffles}

TUPAIA BELANGERI CHINENSIS Anderson

Tupaia chinensis ANDERson, Zool. Res. West. Yunnan, 1879, p. 129 (Ponsee, Kakhyen Hills, western Yunnan, China).

Specimens.-Four, from the following localities in Yunnan: Yunlung, Tsaochiang, Likiang plain, and the fourth from an unknown locality.

The coloration of three of these specimens is of an exceedingly grayish cast, but that from Likiang is more ochraceous. Sufficient Chinese examples of this genus are not yet available for an adequate understanding of the geographic variation occurring. Undoubtedly there yet remain one or more forms to be described.

TUPAIA BELANGERI MODESTA J. A. Allen

Tupaia modesta J. A. Allen, Bull. Amer. Mus, Nat. Hist., vol. 22, 1906, p. 481 (Leimuimon, Hainan, China).

Specimen.-One, from Kachek, Hainan.

This is a flat skin in poor condition but the skull is perfect.

\section{Family ERINACEIDAE}

\section{Genus NEOTETRACUS Trouessart}

\section{NEOTETRACUS SINENSIS Trouessart}

Neotetracus sinensis Trouessart, Ann. Mag. Nat. Hist., ser. 8, vol. 4, 1909, p. 390 (Tatsienlu, Szechwan, China).

Specimen.-One, from Homushu Pass, probably Szechwan.

This is the only specimen of this interesting genus in the National collection. It was obtained by exchange with the American Museum of Natural History. 


\section{Genus ERINACEUS Linnaeus}

\section{ERINACEUS AMURENSIS Schrenck}

Erinaceus amurensis Schrenck, Reis. Amur-Lande, vol. 1, 1858, p. 10 (Amur, Siberia).

Specimen.-One, from 60 miles southwest of Kirin, Manchuria.

The hedgehogs of this region remain properly to be worked out. $E$. orientalis and usurriensis are of the europeaus type of marking, while chinensis resembles, and is probably the same as, dealbatus. E. koreanus, which is doubtfully valid, is said to have the shoulders white. Differences in the claws, as given by Lonnberg (1922), are probably not trustworthy. Finally koreanus is said to have the dorsum much darker than typical amurensis, and undoubtedly darker than the present specimen. On the whole, the coloration of this Kirin skin is much like specimens of hanensis from Hunan, but the skull is smaller, with the bullae weaker and lower.

\section{ERINACEUS DEALBATUS Swinhoe}

Erinaceus dealbatus Swinhoe, Proc. Zool. Soc. London, 1870, p. 450 (Peking, Chihli, China).

Specimens.-Two, from Tientsin, Chihli.

One of these specimens is an immature with all spines virtually white, so that one suspects it may be a partial albino.

\section{ERINACEUS HANENSIS Matschie}

Erinaceus hanesis Matschie, Wissens. Erg. Exped. Filchner China und Tibet, vol. 1, pt. 1, 1908, p. 138 (Hankow, Hupeh, China).

Specimens.-Five skins and six skulls: two from Shanghai, Kiangsu; one from Ningpo, Chekiang; and two, with additional skull, from Yochow, Hunan.

The Hunan specimens are presumed to be typical of hanensis, which seems to be a valid race. The wholly white spines are rather numerous and the darker ones are quite brown, but paler than in examples from nearer the coast, which are without measurements.

\section{Genus HEMIECHINUS Fitzinger}

\section{HEMIECHINUS ALBULUS ALASCHANICUS Satunin}

Hemiechimus albulus alaschanious Satunin, Ann. Mus. Zool. St. Petersb., vol. 11, 1906, p. 181 (Alashan, Mongolian-Kansu border, China).

Specimens.-Four, from northwest of Ninghsia, Kansu.

These examples are from near the type locality. As the describer states, they are paler than typicus, the silky hairs of the underparts being virtually pure white. The skull is also smaller and narrower and the premaxillary tips extend farther caudad. This race is larger 
than minor and the concavity of the postglenoid process extends onto the mastoid in a fashion that is not found in that form. The species miodon is evidently entirely distinct.

\section{Family TALPIDAE}

\section{Genus UROPSILUS Milne-Edwards \\ UROPSILUS SORICIPES Milne-Edwards}

Uropsilus soricipes Milne-Edwards, Nouv. Arch. Mus., 1871, p. 92 (Muping, Szechwan, China).

Specimen.-One, from Taochow, the province given as Szechwan, but I know of no locality of this name save in Kansu.

In recording Zappey's specimens, G. M. Allen (1912) called attention to the great dental variation shown by this series of insectivores, indicating that this covered the characters of the genus Rhynchonax Thomas. Later (1923), however, he recognized this as a valid genus. The single specimen before me was one of the Zappey series and it has 18 teeth in the upper series and the same number below, the former agreeing with Uropsitus, and the latter with Rhynchonax (rather than Nasillus). Until some one has access to sufficient material to settle the moot points involved, I prefer to adopt a conservative attitude.

\section{Genus MOGERA Pomel \\ MOGERA LATOUCHEI Thomas}

Mogera latouchei Tномаs, Proc. Zool. Soc. London, 1907, p. 463 (Kuatun, Fukien, China).

Specimens.-Two; from Kuatun, Fukien, and Tseogiakeo, Szechwan.

In the above topotype the first upper premolar is a trifle longer than the second-not shorter as stated by Thomas. The skull of the Szechwan specimen has a broader interpterygoid and smaller bullae, and it seems likely that when an adequate series is available separation will prove desirable.

\section{MOGERA ROBUSTA (Nehring)}

Talpa robusta Nehrivg, Sitz.-Berich. Gesellsch, Naturf. Freunde, 1891, p. 95 (Vladivostok, Siberia).

Specimen.-One, from Fengtien, Manchuria.

This specimen lacks a skull but comparison of its fore feet with those of coreana leaves little doubt as to its identity.

MOGERA COREANA Thomas

Mogera coreana Thомаs, Proc. Zool. Soc. London, 1907, p. 463 (65 miles northeast of Seoul, Korea).

Specimens.-Four, from Fusan, Korea. 


\section{Genus SCAPTOCHIRUS Milne-Edwards}

\section{SCAPTOCHIRUS GILLIESI Thomas}

Scaptochirus gilliesi Thomas, Ann. Mag. Nat. Hist., ser. 8, vol. 5, 1910, p. 350 (Hotsin, Shansi, China).

Specimens.-Six: 1 from Yulingfu, Shensi; 1 from Taiyuanfu, Shansi; and 4 from 20 miles west of Ningwufu, Shansi.

One of these is especially pale and so old that most of the enamel is worn from the teeth.

\section{SCAPTOCHIRUS LEPTURUS (Thomas)}

Talpa leptura Thomas, Ann. Mag. Nat. Hist., ser. 5, vol. 7, 1881, p. 470 (Peking, Chihli, China).

Specimen.-One skull from Heisui, Manchuria.

The skin of this specimen is missing and as the skull is apparently somewhat immature, identity can be but provisional.

\section{Genus SCAPANULUS Thomas}

\section{SCAPANULUS OWENI Thomas}

Scapanulus oweni Thомаs, Ann. Mag. Nat. Hist., ser. 8, vol. 10, 1912, p. 397 (23 miles east of Taochow, Kansu, China).

Specimen.-One from Archuen, Minshan Mountains, Kansu.

This specimen matches the description of this species in all particulars.

\section{Family SORICIDAE \\ Genus SOREX Linnaeus SOREX ANNEXUS Thomas}

Sorex annexus Thomas, Proc. Zool. Soc. London, 1906, p. 859 (Mingyong, 110 miles southeast of Seoul, Korea).

Specimen.-One from the Sungaree River, Manchuria.

\section{SOREX BEDFORDIAE BEDFORDIAE Thomas}

Sorex bedfordiae Thomas, Abst. Proc. Zool. Soc. London, No. 90, 1911, p. 3 (Mt. Omei, Szechwan, China).

Specimen.-One from Washan, Szechwan.

This is a poor skin without measurements and the skull is damaged, so that an exact determination is impossible. But in coloration and dental characters it agrees with bedfordice.

\section{Genus BLARINELLA. Thomas}

\section{BLARINELLA WARDI Thomas}

Blarinella wardi Thомаs, Ann. Mag. Nat. Hist., ser. 8, vol. 15, 1915, p. 336 (Hpimaw, Upper Burma).

Specimen.-One from the Likiang Mountains, Yunnan.

This specimen, obtained in exchange from the American Museum, is the only representative of its genus in the national collection, and 
G. M. Allen's original identification is accepted without comment. It may be mentioned, however, that Cabrera (1925) was mistaken in assigning as a generic character the presence upon the anterior mandibular incisor of but one denticle, for the dorsal border of this tooth is serrated.

\section{Genus SUNCUS Ehrenberg}

\section{SUNCUS MYOSURUS (Pallas)}

Sorex myosurus Pallas, Acta Acad. Petrop., vol. 10, 1785, p. 327.

Specimens.-Twenty-seven from the following localities in Fukien: Foochow, 8; Futsing (30 miles south of Foochow), 13; 70 miles southwest of Yenpingfu, 4; Kulingsu Island, near Amoy, 2, including one spirit specimen.

This is the "Pachyura murina" of authors, but J. A. Allen (1906) called attention to the fact that this specific name of Linnaeus' is not determinable among the several species of large shrews inhabiting Java. In searching for a name recourse was then had to albinus Blyth as listed as a subspecies of indicus by Cabrera (1925). This proves, however, to be no name, for Blyth merely stated that an albino was secured at Amoy. I therefore follow Cabrera (1922) in using the name myosurus for the Chinese animal. This course, notwithstanding, can be merely tentative until a revision of the Asiatic mainland forms of musk-shrew has been undertaken.

The skin from Kulingsu Island is a partial " albino," lacking black pigment and thus being entirely buffy. The spirit specimen from the latter locality, after the pelage had been dried, proved to be browner than mainland examples but it is extremely unlikely that there is a distinct race of such a wide-ranging species upon this small island so close to the mainland.

\section{Genus CROCIDURA Wagler}

\section{CROCIDURA ATTENUATA ATTENUATA Milne-Edwards}

Crocidura attenuata Mrlne-Edwards, Nouv. Arch. Mus., 1871, p. 91 (Muping. Sizechwan, China).

Specimens.-Five; two from Yochow, Hunan; and three, including two in spirits, from Suifu, Szechwan.

It is assumed that the Hunan skins are fairly typical. At any rate they differ from grisea in having the hind foot a trifle longer and in being slightly less gray, or browner. The Suifu skin was made up from a shrunken, salted pelt, and its skull is broken, so little can be told about it.

CROCIDURA ATtenUata grisea A. B. Howell

Crocidura grisea A. B. Howelt, Proc. Biol. Soc. Wash., vol. 39, 1926, p. 137 (75 miles southwest of Yenpingfu, Fukien, China). 
Specimens.-Four, from the following localities in Fukien; 70 and 75 miles southwest of Yenpingfu, 3 (including the type); and Kuliang, near Foochow, 1.

A typographical error in the original description gave the maxillary tooth row of the type as 6.5 instead of $8 \mathrm{~mm}$.

\section{CROCIDURA COREAE Thomas}

Crocidura coreae Tномаs, Proc. Zool. Soc. London, 1907, p. 860 (Mingyong, 110 miles southeast of Seoul, Korea).

Specimens.-Six: 3 from 5 miles south of Taiyuanfu, Shansi; and 3 in spirits from Fusan, Korea.

The three skins seem to be fairly typical of this palish, gray-brown species with whitish belly and bicolored tail-the only small whitefooted Crocidura of this part of China. The only Fusan skull that has been removed and cleaned differs from the Shansi examples only in points which are believed to be of minor importance; but the pelage is so faded after its immersion in the preservative for 40 years that the present color signifies nothing.

\section{CROCIDURA DRACULA GRISCESCENS A. B. Howell}

Crocidura griscescens A. B. HowelL, Journ. Mamm., vol. 9, 1928, p. 60 (Kuatun, Fukien, China).

Specimens.-Two, the type and a topotype.

This is undoubtedly a small, browner, eastern race of dracula, as already mentioned.

\section{CROCIDURA LASIURA Hodgson}

Crocidura lasiura Hodgson, Ann. Mag. Nat. Hist., ser. 6, vol. 5, 1890, p. 31 (Ussuri River, Manchuria).

Specimens.-Five; four from the Sungaree River, Manchuria, and a skull only from Fusan, Korea.

The above skins of this large, dark, rather short-tailed species are in summer pelage. One of the males is unusually large, measuring 104 (head and body) by 48 by $16.5 \mathrm{~mm}$.

\section{CROCIDURA RAPAX G. M. Allen}

Crocidura rapax G. M. Allen, Amer. Mus. Nov., No. 100, 1923, p. 9 (Yingpankai, Mekong River, southern Yunnan, China).

Specimens.-Five, from Yochow, Hunan.

These apparently are perfectly typical.

\section{CROCIDURA SHANTUNGENSIS Miller}

Crocidura shantungensis MrLler, Proc. Biol. Soc. Wash., vol. 14, 1901, p. 158 (Chimeh, Shantung, China).

Specimen.-One, the type. 


\section{Genus ANOUROSOREX Milne-Edwards}

\section{ANOUROSOREX SQUAMIPES SQUAMIPES Milne-Edwards}

Anourosorex squamipes Mrnne-Edwards, Comptes Rendus Acad. Sci. Paris, vol. 70,1870 , p. 341 (Szechwan and Tibet).

Specimens.-Nine; 2 from Wanshan, and 7, including 3 in spirits, from Suifu, both in Szechwan.

The Suifu skins are in rather harsh pelage and lack brown cheek marks, but G. M. Allen has kindly compared them with the good series of this genus in the Museum of Comparative Zoölogy and pronounced them as belonging to the typical race.

\section{Genus CHIMARROGALE Anderson \\ CHIMARROGALE HIMALAYICA (Gray)}

Crossopus himalayicus Grar, Ann. Mag. Nat. Hist., vol. 10, 1842, p. 261. Specimen.-One from the Likiang Mountains at 10,000 feet, Yunnan.

This animal is evidently extremely rare in China.

\section{Order CHIROPTERA}

\section{Family EMBALLONURIDAE}

\section{Genus TAPHOZOUS Geoffroy}

\section{TAPHOZOUS SOLIFER Hollister}

Taphozous solifer Hollister, Proc. Biol. Soc. Wash., vol. 26, 1913, p. 157 (near Peking, Chihli, China).

Specimens.-Nine, including the type, from the type locality.

\section{Family RHINOLOPHIDAE}

\section{Genus RHINOLOPHUS Lacépède}

\section{RHINOLOPHUS BLYTHI CALIDUS G. M. Allen}

Rhinolophus blythi calidus G. M. Arten, Amer. Mus. Nov., No. 85, 1923, p. 1 (Yenpingfu, Fukien, China).

Specimens.-Seventeen from the following localities in Fukien: Yenpingfu 15 and Futsing 2.

The topotypes are in perfect accord with the measurements given by the describer. Those in spirits are very similar to European examples of $R$. hipposideros save that the metacarpal formula is different, and in the Fukien bats the border of the ear is less sharply concave, the horseshoe is a trifle larger, sella broader and lancet high and much wider. The skull differences are very slight, the chief one being the broader interorbital. 


\section{RHINOLOPHUS BLYTHI SZECHWANUS Anderson}

[Rhinolophus] [blythi] szechwanus Andenson, Ann. Mag. Nat. Hist., ser. 9, vol. 2, 1918, p. 377 (Chunking, Szechwan, China).

Specimens.-Seven in spirits from Suifu, Szechwan.

I am not entirely convinced that this disposition of the above material is correct, but no other course is practicable at present. They clearly have no ciose affinity with the macrotis or hipposideros groups. From Fukien examples of $R$. $b$. calidus they differ in longer forearm (average $41.8 \mathrm{~mm}$.), broader horseshoe, higher sella, and appreciably larger foot and thumb. The skulls are virtually indistinguishable.

\section{RHINOLOPHUS ROUXI SINICUS Anderson}

Rhinolophus rouxi sinicus Anderson, Proc. Zool. Soc. London, 1905, p. 98 (Chintah, Anhwei, China).

Specimens.-Forty-one from the following localities in Fukien: Yenpingfu, 40, including 25 in spirits; 1 from Foochow in spirits.

On the whole the above specimens are nearest this race, although there are some variations, as longer tail. The skull of the Foochow example does not seem to be typical, but as it was removed from the alcoholic and is in bad condition, little can be told from it.

\section{RHINOLOPHUS AFFINIS MACRURUS Anderson}

Rhinolophus affinis macrurus Anderson, Proc. Zool. Soc. London, 1905, p. 103 (Taño, Karennee, Burma, India).

Specimens.-Six, including one in spirits, from Yenpingfu, Fukien. The phalangeal formula places these skins with the affinis rather than the pearsoni group. It seems likely that the Chinese animals will eventually prove to be distinct, but for the present, on the basis of measurements given by Anderson, the Fukien material must be referred to this race rather than to himalayanus.

\section{Family HIPPOSIDERIDAE}

\section{Genus HIPPOSIDEROS Gray}

\section{HIPPOSIDEROS GENTILIS SINENSIS Anderson}

(Hipposideros) $g$ (entilis) sinensis Anderson, Ann. Mag. Nat. Hist., ser. 9, vol. 2, 1918, p. 380 (Foochow, Fukien, China).

Specimens.-Fifteen, including five in spirits, from Yenpingfu, Fukien.

Anderson's terse characterization of this race is anything but satisfactory, but sinensis is the only small member of this genus to have been described from China. 


\section{HIPPOSIDEROS PRATTI Thomas}

Hipposideros pratti Thomas, Ann. Mag. Nat. Hist., ser. 6, vol. 7, 1891, p. 527 (Kiating, Szechwan, China).

Specimens.-Thirty: 11 from Changshowkai, Hunan; 1 skull from Futsing, and 19 from Yenpingfu, Fukien.

The Hunan examples are a trifle smaller than those from Fukien. Two of them are considerably more sooty than any in the series from farther east. It is interesting to find that this fine species occurs near the coast of China. Thomas' description was evidently based upon a single spirit specimen; hence, no reliable color characters could then be offered, and no skull characters were given. In view of these facts it is at present impossible to differentiate subspecifically these coast specimens, although it is not improbable that such a course may prove desirable in the future. Average measurements of 14 females and 1 male are: Head and body, 99.4 ; forearm, 88.5 ; shank, 34.3 ; tail, 58.3 ; ear, 33.3 ; foot, 20 ; thumb, 11.8; length of skull, 32.6 ; palatal length, 4.6 ; pterygoid width; 4.6 ; and narial width, $6.5 \mathrm{~mm}$. The averages of metacarpal length for several specimens are: second, 66.2 ; third, 63 ; and fourth, $63 \mathrm{~mm}$.

Superficially the present series of skins might easily be mistaken for swinhoii, but further examination discloses many fundamental differences. The character that at once distinguishes pratti from any other bat of this genus now known is the form of the skin folds upon either side of the nasal sac. In dried skins these are not so apparent, but they serve to identify spirit specimens at a glance. This species evidently does not belong to the armiger group, but both because of the superficial resemblance which it bears to the latter and their occurrence not only in the same locality but evidently in the same caves, it seems advisable to offer comparisons.

In describing pratti Thomas stated that in size it is exceeded by only three members of the genus. But the type is a female that is smaller than any of those at hand. These coast examples are, then. close to the maximum size for the genus and are larger in head-andbody length than swinhoii. In comparison with the last-mentioned, pratti is slightly larger, with shorter forearm and shank, much longer foot and thumb, and broader ear. In the skull the frontal declivity is concave instead of being almost straight, the rostrum and narial openings are much broader and the rostral borders diverge instead of being parallel as in swinhoii. The palate is shorter, interpterygoid width greater, width of basisphenoid less, and sphenoidal foramina larger, these being conspicuous in ventral view instead of almost hidden as in swinhoii. $H$. pratti as represented shows indications of being a dichromatic species, for two of the skins are in a sooty grayish phase and there is one quite as bright reddish as anv 
specimen of swinhoii; but the remainder are intermediate in tone. The hairs of the head and shoulders of pratti almost entirely lack the darker tips to the hairs such as occur over the remainder of the body, thus rendering the specimens lighter anteriorly. This is so to a considerably greater degree than in swinhoii. The nasal details of the spirit specimens are substantially as given by Thomas. They are not, however, more pronounced in the single male alcoholic than in the females, as might be inferred to be the case.

\section{HIPPOSIDEROS ARMIGER ARMIGER (Hodgson)}

Rh(nolphus) armiger Hodgson, Journ. Asiastic Soc. Bengal, vol. 4, 1835, p. 699 (central region of Nepal, India).

Specimens.-Seven: from Kiating, 1, Suifu, 1, and Hwangtsaopa, 1, all in Szechwan; and from Changshowkai, Hunan, 4.

The specimen from Hwangtsaopa is as small as any swinhoii but is identified on geographic grounds.

\section{HIPPOSIDEROS ARMIGER SWINHOII (Peters)}

Phyllorhina swinhoii Peters, Proc. Zool. Soc. London, 1870, p. 616 (Amoy, Fukien, China).

Specimens.-Twenty-three, including 9 in spirits, from Yenpingfu, Fukien.

For comparison with pratti average measurements of 14 females are given as follows: Length of head and body, 96.6; forearm, 93; shank, 39; tail, 59; ear, 33.5; foot, 16.9 ; thumb, 9.9; length of skull, 31.8; palatal length, 5.4; pterygoid width, 3.5 ; and narial width, $5.1 \mathrm{~mm}$.

Andersen did not recognize the race swinhoii, but with access apparently to a larger series of skins G. M. Allen (1923) considered it to be a valid form, based on brighter color, typifying the coastal representative of the armiger group. The specimens before me do not altogether bear out this statement. It is true that some of the Fukien skins are much brighter than are four from Hunan, but definite dichromatism is indicated and six of the lot from the former province are smoky gray, while four may be said to be intermediate. A difference is found in the ground color of the pelage, however, which is paler and more buffy in four Hunan skins than in any of those from Fukien; and the former are appreciably larger, both in body and skull.

It may be mentioned that judging from the rather scanty representation of bats of the $H$. diadema group in the national collection, races of $H$. armiger appear to differ in having the border of the bony palate definitely $V$ instead of $U$ shaped, and in having the borders of the basisphenoid and basioccipital parallel. 


\section{Genus COELOPS Blyth}

COELOPS INFLATA Miller

Coelops inflata Mrluer, Proc. Biol. Soc. Wash., vol. 41, 1928, p. 85 (near Yenpingfu, Fukien, China).

Specimen.-One, the type.

\section{Family VESPERTILIONIDAE}

\section{Genus MYOTIS Kaup}

Myotis CHINENSIS LUCTUOSUS G. M. Allen

Myotis chinensis luctuosus G. M. Alten, Amer. Mus. Nov., No. 85, 1923, p. 5 (Wanhsien, Szechwan, China).

Specimens.-Seven: Yenpingfu, Fukien, 1; Hwangtsaopa, Keichow, 1 ; and Changshowkai, Hunan, 5.

These all conform to the characters mentioned in the original description.

\section{MYOTIS DAVIDII (Peters)}

Vespertilio davidii Peters, Monatsb, Akad. Wissensch. Berlin, 1869, p. 402 (Peking, Chihli, China).

Specimien-One from Hsinlingshan, Chihli.

This bat is very like $M$. daubentonii but is a trifle darker and the second premolar, both above and below, is internal and excessively crowded.

\section{MYOTIS FORMOSUS (Hodgson)}

Vespertilio formosus Hodgson, Journ. Asiatic Soc. Bengal, vol. 4, 1835, p. 700 (Formosa).

The mainland bat of this rufous and black type has been described under the name mufo-niger Tomes, but I believe that the validity of the latter has not been satisfactorily established. The National Museum has two alcoholics from Formosa and in comparison with these the characters of the ear, which Tomes ascribed to the Chinese animal, are not discernable.

\section{MYOTIS HIRSUTUS A. B. Howell}

Myotis hirsutus A. B. Hownl, Proc. Biol. Soc. Wash., vol. 39, 1926, p. 139 (near Yenpingfu, Fukien, China.)

Specimens.-Thirteen, including the type, from Yenpingfu.

This seems to be the Chinese representative of the European Myotis capaccinii and the relationship may ultimately prove to be only subspecific. Average measurements of 12 specimens are as follows: Length of head and body, 48; tail, 39; ear, 15; forearm, 39 ; thumb, 6.8; shank, 15.1; foot, 10.4; total length of skull, 15.1; 
palatal length, 6.6 ; mastoid width, 7.5 ; and maxillary tooth row, $6.7 \mathrm{~mm}$.

\section{MYOTIS IKONNIKOVI Ognev}

Myotis ikonnikovi Ognev, Ann. Mus. Zool. Acad. Imp. Sci. St. Petersb., vol. 16, 1911 (1912), p. 477 (Evseevka, Priamur Govt., Siberia).

Specimen.-One from Imienpo, Kirin, Manchuria.

As cranial characters were not given in the original description of this form identification must be tentative; but the dimensions are smaller (forearm $31 \mathrm{~mm}$.) than gracitis or any other bat which it might possibly be. It is darker as well as smaller than $M$. mystacinus and its skull is a smaller replica of the latter.

MYOTIS SOWERBYI A. B. Howell

Myotis sowerbyi A. B. Howed,, Proc. Biol. Soc. Wash., vol. 39, 1926, p. 138 (near Yenpingfu, Fukien, China).

Specimens.-Fifty-four: 1 from Foochow and the remainder (with the type), including 38 in spirits, from near Yenpingfu, Fukien.

As indicated in the original description, this bat shows considerable resemblance to $M$. mystacinus of Europe but differs chiefly in the small size of the lower incisor and large size of the first lower premolar. Average measurements of 2 male and 13 female topotypes are as follows: Length of head and body, 41.3; tail, 38.6; ear, 12.3; forearm, 34.8; thumb, 5.8; shank, 15 ; foot, 7.9 ; total length of skull, 13.2 ; palatal length, 5.5 ; mastoid width, 6.8 ; and maxillary tooth row, $5.7 \mathrm{~mm}$.

\section{Genus PIPISTRELLUS Kaup}

\section{PIPISTRELLUS TRALATITIUS PUMILOIDES (Tomes)}

Scotophilus pumiloides Tomes, Proc. Zool. Soc. London, 1857, p. 51 (China).

Specimens.-Twenty-three: Shanghai, Kiangsu, 2; 70 miles southwest of Yenpingfu, Fukien, 2; Kachek, Hainan, 4; and Yochow, Hunan, 15.

In determining the south China pipistrelles I was glad to avail myself of the advice of G. M. Allen. He refers those of the tralatitius type to this race and considers that the Hunan material varies toward abramus. The smaller upper premolar is crowded and not visible from the side. Attention may be called to the error made by J.A. Allen (1906) in recording two species of Myotis from the island of Hainan, for his "Myotis abramus," included in his list on Swinhoes' authority, is clearly a Pipistrellus. It was merely an oversight, for he compares his $P$. portensis with Pipistrellus abramus. 


\section{PIPISTRELLUS TRALATITIUS ABRAMUS (Temminck)}

Vespertilio abramus Temminck, Monog. Mamm., vol. 2, 1835, p. 232 (Japan).

Specimens.-Seven : 5 from Tientsin and 2 from Peking, Chihli.

The variation, especially in the skull, in typical material from Japan is very great, and the north China pipistrelles of this type evidently fall well within this range.

\section{PIPISTRELlUS PULVERATUS (Peters)}

Vesperugo pulveratus Perers, Proc. Zool. Soc. London, 1870, p. 618 (Amoy, Fukien, China).

Specimens.-Eighteen: Pingkiang, Hunan, 17; and Suifu, Szechwan, 1.

Both sexes of this grizzled, blackish pipistrelle are represented. The forearm length of males is close to 33 and of females $36 \mathrm{~mm}$. The Suifu specimen can be identified only approximately, as there are no measurements and the forearms and skull are both broken.

\section{PIPISTRELLUS species}

There are at hand eight Chinese specimens of this genus which are not determinable at present. One, from Kuyuanchow, Kansu, is somewhat of the $P$. savii type, although the skull is smaller. The small upper premolar is very slender, long, and crowded, and it has been suggested to me that this may be an unusually persistent milk tooth, and that in reality it represents a very small species of Eptesicus. It does not resemble any milk tooth of the latter genus that I have examined and it hardly seems likely that such a milk tooth would persist equally on both sides of an adult bat; and there is nothing about the skin to indicate that it is not a pipistrelle. On the other hand, with the present dearth of Siberian material, I am unwilling to risk a specific identification of such a questionable specimen.

The remaining seven specimens are of small pipistrelles with forearm about $30 \mathrm{~mm}$. or less. Four of them are spirit specimens and the fifth is a poor skin with imperfect skull. Of the two good specimens one seems unquestionably to represent a very dark sooty, rather than brownish, race of $P$. pipistrellus, but there is no name available, with description to fit, and it, of course, should not receive a new name on the basis of a single specimen. The other specimen is a slightly larger but equally sooty animal (forearm $30.5 \mathrm{~mm}$.) with larger skull and small premolar internal to the tooth row. It is evidently of the $P$. coromandra type, but the lack of comparative material cuts short further inquiry. 


\section{Genus NYCTALUS Lesson}

\section{NYCTALUS MAXIMUS AVIATOR Thomas}

Nyctalus maximus aviator Thомаs, Ann. Mag. Nat. Hist., ser. 8, vol. 8, 1911, p. 380 (Tokyo, Hondo, Japan).

Specimens.-Four in spirits from Fusan, Korea.

These examples are evidently indistinguishable from typical.

\section{NYCTALUS NOCTULA SINENSIS (Peters)}

Vesperus sinensis Peters, Monatsb. Akad. Wissensch. Berlin (1880), 1881, p. 258 (Peking, Chihli, China).

Specimen.-One in spirits from Hunan.

Comparative material is lacking but it is likely that the present example, of the noctula type, is closer to sinensis than to labiata of Nepal. Externally it is very close to typical European noctula but the skull is somewhat smaller.

\section{NYCTALUS species}

\section{Specimens.-Two from Mount Omei, Szechwan.}

These comprise an immature and a newborn young. The former is at an indeterminate stage of growth and the skull is imperfect, but it seems to belong to a smaller form than noctula and possibly represents an Asiatic race of leisleri.

\section{Genus EPTESICUS Rafinesque}

\section{EPTESICUS SEROTINUS PALLENS Miller}

Eptesicus serotinus pallens Mrller, Proc. Biol. Soc. Wash., vol. 24, 1911, p. 53 (Chengyuanhsien, Kansu, China).

Specimens.-Seventeen: Chengyuanhsien, Kansu, 1 (the type); Kuyuanchow, Kansu, 1; Haishuisan, 1, and 80 miles south of Yenanfu, Shensi, 2; Tientsin, Chihli, 2; and Tsingtao, Shantung, 10.

All but one of the Shantung specimens are juveniles. This one and the Chihli examples are somewhat darker below than typical pallens, but may be so allocated for the present.

\section{EPTESICUS SEROTINUS subspecies}

Specimens.-Six: Changshowkai, Hunan, 5; and one from Suyki, whose province is unknown-possibly Fukien.

Four of the Hunan specimens are alcoholics. The other two can not be referred to pallens, for they are quite dark, with a different quality of coloration, and the skull-especially that to the Hunan skin-is narrow and rather small. Evidently they are not andersoni, nor can they be called typical serotinus. Without additional 
specimens it would be unjustifiable to separate them and it is better for the present to leave them unnamed.

\section{Genus VESPERTILIO Linnaeus VESPERTILIO MURINUS MURINUS Linnaeus}

(Vespertilio) murimus Linnaeus, Syst. Nat., vol. 1, ed. 10, 1758, p. 32 (Sweden).

Specimens.-Two : 120 miles north of Sansing, Manchuria, 1; and 85 miles north of Lanchow, Kansu, 1.

These are indistinguishable from the limited number of European specimens at hand.

\section{VESPERTILIO MURINUS SUPERANS Thomas}

Vespertilio murinus superans Thомаs, Proc. Zool. Soc. London, 1898, p. 770 (Sesalin, Ichang, Hupeh, China).

Specimens.-Six: Yochow, Hunan, 4; Tientsin, Chihli, 1; eastern China, 1.

These skins are but very slightly larger than true murinus, but the skulls are readily distinguishable by their size, greatest length being about $17 \mathrm{~mm}$.

\section{Genus SCOTOMANES Dobson SCOTOMANES ORNATUS SINENSIS Thomas}

Scotomanes ornatus sinensis Thомаs, Journ. Bombay Nat. Hist. Soc., vol. 27, 1921, p. 772 (Kuatun, Fukien, China).

Specimen.-Three from 50 miles southeast of Yochow, Hunan.

These specimens are the only representatives of the genus in the national collection.

\section{Genus PACHYOTUS Gray}

\section{PACHYOTUS KUHLII INSULARIS (J. A. Allen)}

Scotophilus kuhlii insularis J. A. Allen, Bull. Amer. Mus. Nat. Hist., vol. 22, 1906, p. 485 (Rintoi, or Rinsui, Hainan, China).

Specimens.-Two in spirits from Amoy Island, Fulkien, and Kachek, Hainan.

The virtual topotype from Hainan appears to agree in every particular with the original description, and the Fukien example is indistinguishable except for being somewhat paler, possibly from the action of the preservative.

\section{Genus PLECOTUS Geoffroy}

\section{PLECOTUS SACRIMONTIS G. M. Allen}

Plecotus sacrimontis G. M. AlLen, Bull. Mus. Comp. Zoöl., vol. 52, 1908, p. 50 (Mt. Fuji, Japan).

Specimens.-Nine from Wutingshan, Chihli. 
This series clearly belongs with sacrimontis rather than ariel, but in the absence of typical material the exact amount of variation from the former is unknown.

\section{PLECOTUS ARIEL Thomas}

Plecotus ariel Thomas, Abst. Proc. Zool. Soc. London, 1911, p. 3 (Tatsienlu, Szechwan, China).

Specimen.-One in spirits from Sining, Kansu.

\section{Genus MINIOPTERUS Bonaparte}

\section{MINIOPTERUS SCHREIBERSI PARVIPES G. M. Allen}

Miniopterus schreibersi parvipes G. M. Allew, Amer. Mus. Nov., No. 85, 1923, p. 7 (Yenpingfu, Fukien, China).

Specimens.-Eighteen, from the following Fukien localities: 17 , including one in spirits, from near Yenpingfu, and one from 70 miles southwest of the same place.

The specimen from the last-mentioned locality is extremely darkin fact, to such an extent that it stands in considerable contrast to the other skins of the series. The skull is a shade larger than any of the others as well. These are the only differences, however, and it seems that the only sensible thing to do is to pronounce it an extremely large, dark old male of this race. The remainder of the series is entirely uniform. Compared to the typical race of Europe, parvipes is slightly larger, especially the forearm, but the foot is no smaller. It is also much darker and more sooty, and the skull averages larger.

\section{Genus MURINA Dobson \\ MURINA AURATA Milne-Edwards}

Murina aurata MILne-Edwards, Rech. Mamm., 1872, p. 250 ('Tibet).

Specimen.-One from the Likiang Mountains, Yunnan.

This specimen is without collector's measurements, but the forearm has a length of $29 \mathrm{~mm}$.

\section{MURINA HUTTONI FUSCUS Sowerby}

Murina huttoni fuscus Sowersy, Journ. Mamm., vol. 3, 1922, p. 46 (Imienpo area, Manchuria).

Specimen.-One, the type.

It is questionable whether this form should not stand as a full species.

\section{Order CARNIVORA}

\section{Family URSIDAE}

As a basis for identifying Chinese bears one naturally follows the paper by Sowerby, ${ }^{1}$ the conclusions in which are eminently sound. 


\section{Genus SELENARCTOS Heude}

\section{SELENARCTOS THIBETANUS MUPINENSIS Heude}

Selenarctos mupinensis Heude, Mems. Hist. Nat. Emp. Chinois, vol. 5, 1!01, p. 2 (Muping, Szechwan, China).

\section{Specimen.-One from Suifu, Szechwan.}

This skin and skull is of a cub so young that it can be allocated solely on geographic grounds, following the supposition that this is really the race of southern Szechwan and machneilli the one of the more arid northern part of the province.

\section{SELENARCTOS THIBETANUS WULSINI A. B. Howell}

Selenarctos thibetanus wulsini A. B. Hower, Proc. Biol. Soc. Wash., vol. 41, 1928, p. 115 (Eastern Tombs area, Chihli, China).

Specimen.-Four, the type and three topotypes.

I understand that the forests to the east of Peking are rapidly being destroyed. As it is probable that the present race of the black bear is confined to this district it is not unlikely that it will soon be exterminated.

\section{SELENARCTOS THIBETANUS USSURICUS Heude}

Selenarctos ussuricus Heude, Mems. Hist. Nat. Emp. Chinois, vol. 5, 1901, p. 2 (Ussuri, eastern Manchuria).

Specimens.-Two from the region of Imienpo, Manchuria.

These are a fine pair of adult skulls but only that of the female is accompanied by a skin. The latter specimen is the one upon which Sowerby (1920) based a description of this race.

\section{Genus URSUS Linnaeus}

Sowerby, in his review of the bears of eastern Asia (1920), lists the species of cave bear or grizzly type under the generic name Spelaeus. While the latter is convenient for the purpose of designating group characters of subgeneric degree, I regard it as undesirable to accord it full generic standing. Both of the only two specimens of Chinese brown bears available are of this rather than of the arctos type.

\section{URSUS CAVIFRONS (Heude)}

MLlanarctos cavifrons Heude, Mems. Hist. Nat. Emp. Chinois, vol. 5, 1901, p. 1 (Tsitsihar, northwest Manchuria).

Specimen.-One from the district of Imienpo, Manchuria.

Ognev (1924) called the Manchurian bear of this group mandchuricus Heude, but Sowerby (1920), after examining Heude's types, determined that the latter name applies to the local race of arctos. This immense Imienpo male is described by Sowerby and skull measure- 
ments are given. The last maxillary molar measures $43 \mathrm{~mm}$. in length and 21.4 in width.

\section{URSUS LEUCONYX Severtzow}

Ursus leuconyx Severtzow, Nach. Gesellsch. Moscou, vol. \&, 1873, p. 79 (Altai region, Siberia).

\section{Specimen.-One from near Taochow, Kansu.}

There is nothing in the original description which indubitably places this species in the cave-bear rather than the arctos group. Sowerby (1920) assumed that it belonged in the former because of its light-colored claws. In this he was probably correct and his lead in this respect should be followed for the present. Another nomenclatural possibility is baikalensis Ognev, which seems to belong to the Spelaeus group rather than to arctos, as the describer stated. Its type locality is apparently the Irkutsk part of the Sajan Mountains south of Lake Baikal, and it seems likely that it will prove to be synonymous with leuconyx. The present specimen is a juvenile but a very large race is indicated and the last upper molar has a length of $40 \mathrm{~mm}$. Although unsatisfactorily comparable, there are apparently no important differences between this skull and one from south of Irkutsk that are not attributable to age. There are indicated, however, external differences that are believed to be of subspecific significance, but because of the tender age of this single example and ignorance of the juvenal pelage of undoubted leuconyx, I do not feel justified in making it the basis of a new name. U. leuconyx is said to have white claws while those of the Kansu skin are rather dark horn color. The hairs of the entire head are almost black at base but are so extensively tipped with ochraceous that it appears yellow; and the same to a lesser extent is true of the middle and lower back. There is a broad collar of pure white, from 50 to $100 \mathrm{~mm}$. wide, which also extends over the chest and narrowly upon either side almost to the groin. The suggestion of a light collar is found in many races of Asiatic bears of both types and it is known that this is often more pronounced in the young than the adult. But it is not believed that the young of leuconyx could be so strikingly marked in this respect while the adult largely lacks any white collar, which from the description seems to be the case. That the markings of the Kansu skin are not individually peculiar is shown by the photograph of a specimen from the same general region, apparently identically marked, which occurs in Frank Wallace's "Big Game of Central and West China "; but whether the latter is of an adult or juvenile is not mentioned. 


\section{Family PROCYONIDAE}

\section{Genus AILURUS F. Cuvier \\ AILURUS FULGENS STYANI Thomas}

Ailurus fulgens styani Thомаs, Ann. Mag. Nat. Hist., ser. 7, vol. 10, 1902, p. 251 (Yangliupa, Szechwan, China).

Specimens.-Two; one from Wachin, Szechwan, and the other believed to be from Tibet.

In the description of this race Thomas stressed only the superior size and certain skull differences from typicus. Subsequently (1922) he reported two examples from Yunnan, under the same name, one of which had a black-ringed tail, while both were heavily darkened over the shoulders and withers. This is the condition in the National Museum's Szechwan pelt. In the other, however, this condition is so much intensified, with extensive black areas upon the middle of all the hairs, that it is believed to represent a new race. It is a trade skin, however, without skull or definite locality and too many new names have already been based upon such objectionable material.

\section{Family CANIDAE}

\section{Genus NYCTEREUTES Temminck}

\section{NYCTEREUTES PROCYONOIDES STEGMANNI Matschie}

Nyctereutes stegmanni Matschie, "Wissens. Erg. Exped. Filchner China und Tibet, vol. 10, pt. 1, 1908, p. 180 (Tschonkiang, lower Yangtze).

Specimens.-Four; one from the Likiang Plain, Yunnan, two from Suifu, Szechwan, and one from Chinkiang, Kiangsu.

Upon geographical grounds it seems that the Yunnan specimen should be orestes, but there is no white upon the hairs of the tail and but few of them are tipped with black, while the feet are brown instead of black. The dorsal coloration is, however, considerably brighter than what is believed to be typical of stegmanni. The Kiangsu skin conforms to Matschie's description very well indeed.

\section{NYCTEREUTES PROCYONOIDES USSURIENSIS Matschie}

Nyctereutes ussuriensis Matschie, Wissen. Erg. Exped. Filchner China und Tibet, vol. 10, pt. 1, 1908, p. $17 \mathrm{~S}$ (near Ussuri, Manchuria).

Specimen.-One from northern Manchuria.

This is a large, brightly colored race, with interoccular area no darker than the nose.

\section{Genus VULPES Oken}

A number of the races of Asiatic foxes, including all the Chinese ones, are in such a state of confusion and are so little understood 
that any determination based on scanty material is all but worthless. The specimens at hand, however, may be tentatively disposed of as follows:

\section{VULPES VULPES subspecies}

There is in the National Museum a single skin without skull of a red fox of the usual vulpes type and rather small which is said to be from Korea. Subspecific allocation is impracticable.

\section{VULPES VUlPES MONTANUS (Pearson)}

Canis vulpes montanus Pearson, Journ. Asiatic Soc. Bengal, vol. 5, 1836, p. 313.

Four trade skins without skulls purchased in the vicinity of the China-Tibet boundary had best be referred to this race. One of them especially is very similar to Kashmir skins; the sides are pale and the pelage considerably worn.

\section{VULPES VULPES AURANTIOLUTEUS Matschie}

Vulpes aurantioluteus Matschie, Wissens. Erg. Exped. Filehner China und Tibet, vol. 10, pt. 1, 1908, p. 168 (bought in Tatsienlu, Szechwan, China).

Specimens.-Two; from Suifu, Szechwan, and Minshan Mountains, Kansu. Without having the material to pass upon the validity of this form, these two specimens are referred to it. The one from Kansu, taken in August and much paler than the other, is considerably paler upon the sides and is presumed to be an immature.

\section{Genus CUON Hodgson \\ CUON PRIMAEVUS (Hodgson)}

Canis primaevus Hodgson, As. Res., vol. 18, 1833, p. 221 (middle region of Nepal, India).

Specimen-One from Tseojiakeo, Szechwan.

This example is very red, like the wild $\log$ of India rather than like the lighter dukhunensis of the Himalayas and it seems as though it should certainly be distinct. However, there is no comparative inaterial at hand.

\section{Family MUSTELIDAE}

\section{Genus CHARRONIA Gray}

Until 1918 there was no known character for satisfactorily differentiating this group of martens generically, but in that year Pocock indicated characters of the baculum which are entirely sufficient for this purpose.

\section{CHARRONIA FLAVIGULA BOREALIS (Radde)}

(Mustela flavigula) varietas borealis RADDE, Reise Suden Ost-Sib., vol. 1, 1862 , p. 23 (Amur, Siberia). 
Specimens.-Eight, one being from each of the following localities: An indeterminate spot in Manchuria; Imienpo, Manchuria; Sianfu, Shensi, and 90 miles west southwest thereof; Taiyuanfu, Shansi; Tseogiakeo, Szechwan; and the Salween-Mekong divide in Yunnan.

When sufficient skulls are available it is probable that the north and west China martens may with propriety be resolved into two or more valid forms. The coloration of this species is, however, exceedingly variable and all of the color characters that have been ascribed to the several races named from this area are well within the range of individual variation. Unfortunately, most of the specimens secured are hunters' skins. without skuils or measurements. The two Manchurian pelts differ from each other fully as much as they do from the Shensi individuals and can not be called koreana. The one from Shansi is not greatly different from another from Fukien provisionally called kuatunensis. The Yunnan skin is very dull colored and that from Szechwan very bright; and they exhibit no characters by which szetchuensis might be recognized.

\section{CHARRONIA FLAVIGULA KUATUNENSIS (Bonhote)}

Mustela flavigula kuatunensis Bonноте, Ann. Mag. Nat. Hist., ser. 7, vol. 7, 1901, p. 348 (Kuatun, Fukien, China).

Specimen.-One from 75 miles southwest of Yenpingfu, Fukien.

This identification is but tentative as the validity of the race has not yet been established. The above example differs from true flavigula only in the slightly darker underparts.

\section{Genus MUSTELA Linnaeus \\ MUSTELA NIVALIS MOSANENSIS Mori}

Mustela nivatis mosanensis MorI, Journ. Chosen Nat. Hist. Soc., 1927, p. 1 (Yengan, near Mosan, northeast Korea).

Specimen.-One from 60 miles southwest of Kirin, Manchuria.

This fine skin without skull is markedly smaller ( 177 by 38 by 24 mm.) than the measurements given by Mori and should not be considered as typical; but it is definitely not pygmaea. It is darker than any of the considerable number of true nivalis in the national collection and can be matched (and exactly) only by certain skins of the American species rixosa.

\section{MUSTELA species}

Specimens.-Two, from 70 miles northwest of Taiyuanfu, Shansi, and 40 miles west of Sining, Kansu.

These two specimens of small weasels belong to entirely different groups. As there is not a single other comparable specimen in the 
National Museum from any portion of Asia I deem it preferable to make no attempt to name them for the present.

\section{MUSTELA SIBIRICA SIBIRICA Pallas}

Mustela sibirica Parlas, Spicil. Zool., vol. 14, 1780, p. S6 (eastern Siberia).

Specimens.-Six; one each from Tientsin and Peking, Chihli; 2 from near Sianfu, Shensi; and 2 from near Taiyuanfu, Shansi.

As with the other weasels, the nomenclature of the Chinese minks is not easy of proper disposition, but the material at hand is adequate to show that it is separable into four races. It is well known that the brown summer pelage of these animals is very different from the bright winter coat. Coloration seems to be quite uniform when one has specimens in similar pelage from a single geographic area. The difficulty is encountered when individuals in changing pelage are to be allocated; and there seems to be some little variation with age.

No undoubtedly typical specimens of sibirica are available and it must therefore be presumed that the popular supposition to the effect that Shansi and Shensi material should be so identified is correct. At any rate these skins are separable from the remainder of the specimens on the grounds of pale winter coloration coupled with a minimum of sootiness about the face and no black upon the feet (vs. manchurica). A summer skin from Shensi has a darker tail tip, which is not found upon the one from Tientsin.

\section{MUSTELA SIBIRICA MOUPINENSIS (Milne-Edwards)}

Putorius moupinensis Milne-Edwards, Rech. Mamm., 1872, p. 347 (Muping, Szechwan, China).

Specimens.-Four from Szechwan; Sungpan, 1, and Suifu, 3.

Although October and December skins are represented these are of the dark summer type of coloration, and the former is very much worn. The tone is dark as in the Manchurian race but there is also a definite darkening of the tail tip and the face is less distinctly sooty.

Barrett-Hamilton gave the type locality of his Putorius sibiricus noctis as Sanyentze, China. I can not locate this on any map, but the termination of the name would indicate that it is certainly in Szechwan, and it is hence likely that he described merely the summer pelage of moupinensis.

\section{MUSTELA SIBIRICA DAVIDIANA (Milne-Edwards)}

Putorius davidianus Milne-Edwards, Nouv. Arch. Mus., vol. 7, 1870, p. 92 (Kiangsi).

Specimens.-Seven, from 20 miles east of Taipingfu, Anhwei, 1; Yochow, Hunan, 4; Futsing, Fukien, 1; and Shanghai, Kiangsu, 1. 
It seems probable that the first five of these specimens mentioned are rather typical. These and the Fukien example are in winter pelage, which is much brighter and of a more intense color than occurs in true sibirica. The Shanghai skin is in summer pelage, distinctly darker than comparable sibirica.

\section{MUSTELA SIBIRICA MANCHURICA Brass}

M(ustela) manchurica Brass, Reiche Pelze, 1911, p. 490 (Manchuria).

Specimens.-Seven: Seoul, Korea, 4; Imienpo, 1, and 120 miles northeast of Sansing, 2-both localities in Manchuria.

Winter skins of this race are distinguishable from those of Shansi and Shensi sibirica by the more sooty face and feet. Summer skins may be told from sibirica and davidiana by the darker, richer body color and very dark face. The four Korea skins are juvenal but the two that are in unworn pelage have a peculiar, golden-brown sheen upon the tips of the guard hairs suggestive of some races of beaver (Castor).

\section{MUSTELA TIARATA Hollister}

Mustela tiarata Hollister, Proc. Biol. Soc. Wash., vol. 26, 1913, p. 2 (150 miles east of Lanchow, Kansu).

Specimens.-Seven, from the following localities in Kansu: 150 miles east of Lanchow, 3 (including the type); 10 miles west of Sining, 1 ; and 120 miles south of Lanchow, 3 .

These are all very uniform and much darker than lineiventer.

\section{MUSTELA LINEIVENTER Hollister}

Mustela lineiventer Hollister, Proc. Biol. Soc. Wash., vol. 26, 1913, p. 2 (Little Altai, Siberia).

Specimens.-Two from Shansi : Wutsai, one, and a second from an unknown spot.

No Tibetan examples of larvata are at hand but these two examples do not conform to the descriptions of that animal. On the contrary they match very well the type series of lineiventer. That the latter is but a subspecies seems certain, but whether of the European animal or of larvata remains to be established.

\section{Genus VORMELA Blasius}

\section{VORMELA NEGANS Miller}

Vormela negans Mrller, Proc. U. S. Nat. Mus., vol. 38, 1910, p. 385 (Ordos Desert about 100 miles north of Yulinfu, Shensi, China).

Specimens.-Two (including the type) skins without skulls from the type locality.

In his field notes Mr. Sowerby stated that this is evidently a rare inhabitant of the Ordos. From what he could learn it must 
frequent spots where trees exist and climbs freely, as its native name would signify.

\section{Genus LUTRA Brisson \\ LUTRA LUTRA (Linnaeus)}

(Mustela) lutra Linnaeus, Syst. Nat., vol. 1, ed. 10, 1758, p. 45 (Upsala, Sweden).

Specimens.-Two: a broken skull only from Sianfu, Shensi, and the skin only of a juvenile from Fusan, Korea.

Specimens of Chinese otters are still too scarce to be able to determine the status of the names chinensis and hanensis.

\section{Genus HELICTIS Gray}

\section{HELICTIS MOSCHATA Gray}

Helictis moschata GraY, Proc. Zool. Soc. London, 1831, p. 94 (China).

Specimens.-Two: Shanghai, Kiangsu, 1, and Yochow, Hunan, 1.

The Shanghai example is without skull. The second skin is somewhat similar save that the underparts are pale ochraceous, this darkening in the inguinal region. The skull shows a much greater zygomatic spread than any other available but it is considerably the oldest, and just this variation with age is at times encountered in the case of certain other carnivores (as Martes). For the reason, then, that sufficient is not known regarding the normal variation within this genus the Hunan animal is not named as new, although it is thought probable that this course will prove the desirable one eventually.

\section{HELICTIS MOSCHATA FERREO-GRISEUS Hilheime}

Helictis ferreo-griseus Hnzhermer, Zool. Anz., vol. 29, 1905, p. 298 (bought in Hankow (Hupeh) ; locality unknown).

Specimens.-Four from Szechwan; Kiating, 1; and Suifu, 3.

These four skins, accompanied by but two skulls, conform well to the description of this race, which is probably but subspecifically distinct from moschata. It may be noted, however, that the infraorbital foramina of the Kiating skull are larger, and of the single Suifu skull, quite small.

\section{Genus MELES Brisson}

\section{MELES LEPTORHYNCHUS Milne-Edwards}

Meles leptorhynchus Milne-Edwards, Ann. Soc. Hist. Nat. Paris, vol. 8, 1867, p. 374 (Peking, Chihli, China).

Specimens.-Five: Tientsin and Tabul, Chihli, 1 each; Tao River, Kansu, 1; Taiyuanfu, Shansi, 1; and Yochow, Hunan, 1.

These are quite uniform excepting the juvenile from Hunan, which has the white nose-stripe extending only half way between the nose 
and eyes, thus having one of the characters upon which tsingtauensis was founded. This, however, is variable in this genus and the validity of the latter name, as well as of hanensis, is open to question.

MELES AMURENSIS Schrenck

Meles taxus var. amurensis Schrenck, Reise Amur-land, vol. 1, 1858, pl. 1 (northern Manchuria).

Specimens.-Two from Manchuria-one from the Sungaree River and the other from an unknown locality.

It is probable that amurensis is a good race but a dependable description of it seems to be lacking and specimens scarce. The two in hand are allocated by locality alone for one is a mere baby, very dark except for extensive white tipping of the guard hairs and pure white tail, while the other, which is a trade skin without skull and purchased at Tientsin, is very old. The whole dorsum is yellowish white with darker areas near the ends of the guard hairs only along the middorsum.

\section{Genus ARCTONYX F. Cuvier}

\section{ARCTONYX LEUCOLAEMUS LEUCOLAEMUS (Milne-Edwards)}

Meles (Arctonyx) leucolaemus Milne-Edwards, Rech. Mamm., 1871, p. 195 (Peking, Chihli, China).

Specimens.-Four: 80 miles east of Peking, Chihli, 1; Ningpo, Chekiang, 2; and Kuatun, Fukien, 1.

The specimen from Chihli, which is undoubted leucolaemus, is rather light about the head and the hairs of the posterior half of the dorsum lack white tips, both of which are characters considered to be individually variable. This is fairly between two skins from Ningpo representing two extremes of head coloration. In one there are hardly any dark markings while in the other the white nose stripe extends only to just above the eyes. This illustrates the rashness of coining new names for such carnivores when material is too scanty for gaining a proper appreciation of the range of individual variation.

\section{ARCTONYX LEUCOLAEMUS OBSCURUS Milne-Edwards}

Arctonyx obscurus Milne-Edwards, Rech. Mamm., 1871, p. 338 ("Chinese Tibet"=Yunnan or extreme southwestern Szechwan).

Specimens.-Four; Minshan Mountains, Kansu, 1; Mount Omei, 2, and Washan, 1, both in Szechwan.

I can not see the slightest reason why all the Chinese members of this genus should not be considered as races of a single species. Furthermore, all the external characters, at least of the three forms most recently named-orestes, incultus, and milne-edwardsi-are believed to fall well within the limits of individual variation of these most variable carnivores. In fact, most of these differences occur in 
two specimens at hand from Chekiang as already mentioned. As far as actual differences are concerned, one would be justified in indentifying all my eight Chinese examples as belonging to one race, but it is believed likely that adequate material would show that the west China animal is distinct. The Kansu pelt is very dark with the extreme proximal portion of the hairs black instead of white. But this example is very young and it is known that juveniles of Meles may be considerably darker than adults. The skulls of these specimens are too variable in age to be of much use in the present connection.

\section{Family VIVERRIDAE}

\section{Genus VIVERRA Linnaeus}

\section{VIVERRA ZIBETHA ASHTONI Swinhoe}

Viverra ashtoni SwINHOE, Proc. Zool. Soc. London, 1864, p. 379 (Suykaou, River Min, Fukien, China).

\section{Specimen.-One from Futsing, Fukien.}

This race has at various times been considered as identical with true zibetha. The specimen at hand certainly seems to be subspefically distinct from what is evidently typical of the latter and as it is from near the type locality of ashtoni it seems wiser to call it that. It does not agree very well either with Swinhoe's poorly executed figure or with his description, probably for the reason that the type was evidently in thin summer coat while the present example is in especially luxuriant winter pelage. Details that may be mentioned consist of the absence of dark barring upon the lower shoulders, the dorsal crest as long and as black as typicus, and the pure white rings of the tail.

\section{VIVERRA ZIBETHA FILCHNERI Matschie}

Viverra filchneri Matschie, Wissens, Erg. Exped. Filchner China und Tibet. vol. 10, pt. 1, 1908, p. 192 (Hinganfu, Shensi, China).

Specimens.-Six: 2 each from Wachin and Yachowfu, Szechwan; Yochow, Hunan, 1; and Yunnan, 1.

Five of these are hunter's skins without skulls and it is with some hesitation that they are thus identified. They differ slightly from the Fukien pelt of ashtoni in being paler upon the sides and in having the incipient spots or wavy lines of the flanks somewhat more distinct. But the Fukien pelt is in heavier pelage than any of the others and the apparent differences may be due only to this fact. The Yunnan skin is of a half grown animal and the pale head and neck markings are mostly gray instead of whitish. 


\section{Genus VIVERRICULA Hodgson}

\section{VIVERRICULA PALLIDA Gray}

Viverricula pallida GraY, Hardwicke's Illust. Indian Zool., vol. 2, 1833, p. 34, pl. 6 (China, probably near Canton, Kwangtung).

Specimens.-Four: 2 from Futsing, Fukien; a skeleton only from Nanking, Kiangsu; and 1 from Suifu, Szechwan.

I agree with Allen (1912) in doubting the validity of the race filchneri Matschie, as the characters which were ascribed to it are not such as are reliable. The flat skin without skull from Suifu is more ochraceous than that of Fukien, and the tail is not only shorter but the hairs of the dark rings are broadly tipped with brown over the middorsal part. Great variation in color is known to occur in this genus, however.

\section{Genus PAGUMA Gray}

PAGUMA LARVATA YUNALIS Thomas

Paguma larvata yunalis Thомаs, Ann. Mag. Nat. Hist., ser. 9, vol. 8, 1921, p. 617 (Yenyuensien, Yunnan, China).

Specimens.-Six: 1 from Wahsin and 3 from Suifu, Szechwan; and 2 from an altitude of 10,500 feet in the Likiang Mountains, Yunnan.

The single adult from Szechwan is quite pale and on this character might be referred to the next race. The terminal four-fifths of the tail of the Suifu juvenile is solid black, while that of the Wahsin example, which is equally young, is grayish buffy and without any black at all.

\section{PAGUMA LARVATA RIVALIS Thomas}

Paguma larvata rivalis Thomas, Ann. Mag. Nat. Hist., ser. 9, vol. 8, 1921, p. 618 (Ichang, Yunnan, China).

Specimen.-One from Yochow, Hunan.

This pelt is more tawny than any others of the genus at hand and the black of the nape is represented merely by a slight sootiness in this region. It is undoubtedly different from the other specimens available and closer to the description of rivalis. Whether it is identical with the latter can not be established at this time.

\section{Genus HERPESTES Illiger}

\section{HERPESTES CANCRIVORA HANENSIS (Matschie)}

Urva hanensis Matschie, Wissens. Erg. Exped. Filchner China und Tibet, vol. 10, pt. 1, 1908, p. 190 (Hankow, Hupeh, China).

Specimens.-Three: Ningpo, Chekiang, 1; and Futsing, Fukien, 2.

I can see no reason for according Urva more than subgeneric rank. About the eye and thence extending to the muzzle of these specimens 
there is an area over which the hairs are exceedingly short and rather ochraceous, thus giving to the face a spectaeled appearance. In the Fukien examples the white bands extending from the mouth over the shoulders are very distinct. These are less well marked in the Ningpo specimen, and it is appreciably darker above. This race is accepted tentatively but is open to considerable question.

\section{Family FELIDAE}

\section{Genus FELIS Linnaeus}

\section{FELIS PARDUS FONTANIERII Milne-Edwards}

Felis fontanierii Mrlne-Edwards, Ann. Sei. Nat. Zool., vol. 8, 1867, p. 375 (Peking, Chihli, China).

Specimens.-Three: Taiyuanfu, Shansi, 1; Minchow, Kansu, 1; and Yochow, Hunan, 1 skull only.

The Kansu specimen is fine and very large, while the pelt from Shansi is much smaller and probably immature. The latter gives an appearance of being considerably paler, chiefly because the borders of the rosettes are not continuous in outline while those of the other are.

\section{FELIS UNCIA Schreber}

Felis uncia Schreber, Saug., vol 3, 1778, p. 386, pl. 100.

A fine native skin without skull was purchased by Dr. W. L. Abbott. The locality was said to be Tibet. It is probably in spring pelage as although this is full, it is somewhat worn. The coloration tends toward ochraceous more than seems to be usual in this animal.

\section{FELIS NEBULOSA Griffith}

F'elis nebulosa Griffith, Descript. Vert., 1821, p. 37.

Specimen.-One skin only, from Kachek, Hainan.

This flat hunter's skin, somewhat torn and with part of the tail missing, is the first clouded leopard reported from Hainan since 1870 (Swinhoe) and is of the paler, ochraceous type. The material is not available to judge of the degree of resemblance of this example to typical nebulosa.

\section{FELIS TRISTIS Milne-Edwards}

Felis tristis Mune-Edwards, Rech. Mamm., 1871, p. 223 (China).

A beautiful hunter's skin without skull of this exceedingly rare cat was bought by D. C. Graham at Tatsienlu, Szechwan. One can not tell the degree to which the skin has been stretched during tanning, but this specimen, especially the tail, seems to be definitely larger than what is supposed to be true tristis. It will be referable to semenovi if this be really distinct from tristis, but the type locality 
of the latter is unknown, being merely China, and until series have become available conservatism must be employed.

\section{FELIS TEMMINCKI DOMINICORUM Sclater}

Felis dominicorum Sclater, Proc. Zool. Soc. London, 1898, p. 1 (Foochow, Fukien, China).

Felis (Catopuma) melli Matschie, Archiv Naturgesch, vol. 88, 1922, p. 36 (Not Felis (Neofelis) melli Matschie).

Felis temmincki badiodorsalis A. B. Howell, Proc. Biol. Soc. Wash., vol. 39, 1926, p. 143 (New name for Felis (Catopuma) melli Matschie).

Specimen.-One from Fukien.

By an unfortunate oversight the name dominicorum, listed in the Addenda of Trouessart, was overlooked by me at the time I first endeavored to identify cats of the temmincki group. Hence the name badiodorsatis, which I suggested to replace the preoccupied name melli, must be placed in synonymy, for it is unlikely that there are any tangible differences in cats representative of the above names. The specimen recorded is without date or measurements and the skull is damaged.

\section{FELIS EUPTILURA Elliot}

Felis euptilura ELLIotт, Proc. Zool. Soc. London, 1871, p. 760 (type locality unknown).

Specimens.-Three: Chenkiang, Kiangsu, 1; Hsinglungshan, Chihli, 1 ; and Korea, 1 . •

The Kiangsu and Chihli specimens are in winter coat and are almost identical, with ground color grayish and the bay spots illy defined. The Korean example, on the other hand, is evidently in summer pelage and is markedly ochraceous, which is just such a seasonal difference as one would expect.

\section{FELIS BENGALENSIS Kerr}

Felis bengalensis KerR, Linn. Anim. Kingd., 1792, p. 151 (India).

A skin with skull, presented by Dr. W. L. Abbott and marked "Chinese Turkestan, possibly Tibet" is indistinguishable from the larger, buffier specimens of this animal from India. It is deemed likely that at least most of the small Chinese cats of this general type, such as scripta on the one hand and chinensis on the other, will eventually be found to bear a subspecific relationship to this form. It also seems possible that there may be a blending of characters between chinensis and euptilura, but hardly between the latter and scripta. For the present, the binomial may be used for all these cats.

\section{FELIS SCRIPTA Milne-Edwards}

Felis scripta Mrlne-Edwards, Nouv. Arch. Mus. Hist. Nat., vol. 7, 1871, p. 92 (Muping, Szechwan, China).

$21776-29-3$ 
Specimens.-Seven, Suifu, Szechwan, 6; and Likiang Mountains at 10,000 feet, Yunnan, 1.

The Yunnan specimen is quite a bit different from the others, as the larger spots are broken up into smaller ones, and there are darker, more tawny or "tabby" areas throughout the buff. It is slightly smaller than the average domestic cat, and the possibility of it being a cross with that animal is worth considering. No skull of ingrami was available when this name was proposed by Bonhote and I consider it rather likely that the type of the latter may have been a young individual of scripta.

\section{FELIS CHINENSIS Gray}

Felis chinensis Gray, Mag. Nat. Hist., vol. 1, 1837, p. 577 (China).

Specimen.-One from Yenanfu, Shensi.

This example is in heavy winter coat with dorsal marks darker and better defined than in the specimens assigned to euptilura.

\section{Order PRIMATES}

\section{Family CERCOPITHECIDAE}

\section{Genus PITHECUS Geoffroy and Cuvier}

\section{PITHECUS THIBETANUS (Milne-Edwards)}

Macasus thibetanus Mrlne-Edwards, Compt. Rend. vol. 70, 1870, p. 341 (mountains near Muping, Szechwan, China).

Specimens.-Three from Mount Omei, Szechwan.

This lot consists of a fine male, female, and young. The male is almost black above, smoky brown below, and there is much gray grizzling about the face. The female lacks the latter detail and is browner. The tail in this species is very short and, as seems usual in the large, short-tailed macacques, the posterior nares are relatively very narrow and high. From the descriptions it seems not unlikely that these specimens may be somewhat darker than typical.

\section{PITHeCUS PULlUS A. B. Howell}

Pithecus pullus A. B. Howncl, Proc. Biol. Soc. Wash., vol. 41, 1928, p. 41 (Kuatun, Fukien, China).

Specimen.-One, the type.

This large, short-tailed macacque is related to $P$. thibetanus but is uniformly of a chocolate color with the suggestion of a golden sheen. Its recent discovery in a spot mammalogically so historical as Kuatun indicates the richness of the fauna of this region. 
PITHECUS LASIOTIS (Gray)

Macacus lasiotis Gray, Proc. Zool. Soc. London, 1868, p. 61 (Szechwan, China).

Specimens.-Ten: Chihli, 2; Shanghai, Kiangsu, 3; Mount Omei, 1. Giakeoho, 1, and Suifu, Szechwan, 1; and Ashi, Yunnan, 2.

The Kiangsu specimens are in worn pelage, those from Yunnan very bright, and the remainder duller. The material, however, is entirely inadequate to enable one to judge of the proper disposition of the names tcheliensis and vestitus and as the matter is further complicated by ignorance regarding just which of the specimens were transported captives, the more conservative nomenclature is herewith employed.

\section{Genus PYGATHRIX Geoffroy}

\section{PYGATHRIX species}

Specimens.-Three; purchased in Peking and said to be from Eastern Tombs, Chihli, 1; and bought alive in Shanghai, Kiangsu, 2.

I am not aware that the present genus has been recorded from northern China and it seems extremely likely that the Chihli specimen was brought into the country from elsewhere. It is a young individual, the chin and throat being white and the rump and base of the tail distinctly paler gray than the rest of the back, suggesting $P$. nigripes of Cochin China. On the labels of the two bought alive in Shanghai by Mr. Wulsin is written "Hainan," but it seems most unlikely that they came from this island. The locality of capture therefore is unknown and their characters do not permit of exact determination with the comparative material available. The dorsum is black while the facial markings, shoulder stripes and underparts are dingy gray. There is also a preponderance of these gray hairs upon the hind legs and beneath the tail.

\section{Genus RHINOPITHECUS Milne-Edwards}

\section{RHINOPITHECUS ROXELLANAE (Milne-Edwards)}

Semnopithecus roxellanae MiLne-Edwards, Compt. Rend., vol. 70, 1870, p. 341 (principality of Moupin, Tibet=Muping district, Szechwan, China).

The single hunter's skin, without skull, of an adult female of this interesting and rare monkey was purchased by Doctor Graham from natives in southern Szechwan. He said in his field catalogues that its habitat is said to be in the high mountains north and west of Yachow. 


\section{Order RODENTIA}

\section{Family SCIURIDAE}

\section{Genus MARMOTA Blumenbach}

The Asiatic marmots are in a condition far from orderly and but little can be done with them until much material has been studied.

MARMOTA BOBAC SIBIRICA (Buchner)

A(rctomys) bobac var. sibirica Buchner, Mamm. Przewalski, 1888, p. 39 (south Russia).

Specimens.-Four skulls without skins from north Urga, Mongolia.

MARMOTA CENTRALIS (Thomas)

Arctomys centralis Thomas, Ann. Mag. Nat. Hist., ser. 8, vol. 3, 1909, p. 260 (Mt. Borochoro, northern Sinkiang).

Specimen.-One from near the Kobdo River, Mongolia.

This example was so identified by the late N. Hollister. It matches the description of centralis but no attempt is made to pass upon the relationship of this form.

\section{MARMOTA HIMALAYANA HIMALAYANA (Hodgson)}

Arctomys himalayanus Hodgson, Journ. Asiatic Soc. Bengal., vol. 10, 1841, p. 777 (Tibet).

Specimen.-One from Dytschyu (=Dzachu?), Tibet.

This single specimen is comparable in every way with the lighter examples of a series from Ladak.

\section{MARMOTA HIMALAYANA ROBUSTA (Milne-Edwards)}

Arctomys robusta Milne-Edwards, Nouv. Arch. Mus., vol. 7, 1870, p. 92 (Muping, Szechwan, China).

Specimens.-Thirteen: 1 from Nganyangba, Szechwan, and the remainder from Kansu as follows: Taochow, 7; 100 miles southwest of Lanchow, 3; and Archuen, Minshan Mountains, 1.

It is not known for certain that this race is distinct. G. M. Allen (1912) followed de Winton and Styan in considering it as inseparable from himalayana, but the latter authors did not recognize many races of other genera which according to present day usage are considered to be excellently differentiated. The material at my disposal is undoubtedly representative of robusta as such and it is believed that the differences shown, consisting chiefly of the greater amount of black in the pelage, especially on and about the tail, are sufficient for subspecific recognition. 


\section{Genus CITELLUS Oken}

\section{CITELLUS DAURICUS MONGOLICUS (Milne-Edwards)}

Spermophilus mongolicus MrLne-Edwards, Ann. Sci. Nat., vol. 7, 1867, p. 376 (northwest Chihli, China).

Specimens.-Thirty-two: near Peking, 1, Tientsin, 4, Tabul, 4, and west of Lamamiao, 6-the foregoing in Chihli; Tungkwan, 1, and vicinity of Sianfu, Shensi, 1; Lanchowfu, 12, and Chingningchow, Kansu, 3.

G. M. Allen (1925) stated "specimens obtained-near Peking are therefore topotypes," but this is slightly misleading for Thomas (1908) had already fixed the type locality for this animal as Suanhwafu, Chihli, some 90 miles northwest of Peking. There is great variation in this type of ground squirrel, this apparently being due chiefly to age and to a lesser extent to season. In the skins before me there is fully as much individual as geographic variation, with the palest individual and one of the darkest from the same locality. Hence there is no choice but to call them all the same thing.

\section{CITELLUS EVERSMANNI EVERSMANNI (Brandt)}

Spermophilus eversmanni Brandt, Bull. Acad. Imp. Sci. St. Petersb., vol. 9, 1841 , p. 43.

Specimen.-One from the Tianshan Mountains, Sinkiang.

\section{Genus DREMOMYS Heude}

\section{DREMOMYS PERNYI PERNYI (Milne-Edwards)}

Sciurus pernyi MILne-Eџwards, Rev. Zool., vol. 19, 1867, p. 230 (Szechwan, China).

Specimens.-Nine from Yunnan: From 9,500 to 12,000 feet, Likiang Mountains, 4; Hofuping Mountains, Mekong Valley, 3; Yangtze Mountains, 1; and Chuchi, 1.

The Hofuping and Yangtze Mountain specimens are undoubtedly fairly representative of the typical race of this species but examples from the same locality exhibit appreciable variation in the degree of buffiness shown. The Chuchi skin has a strong overwash of ochraceous upon the whole medial side of the thigh, although the throat is white. It does not approach howelli, mentosus, or imus, and merits separation if the characters which it exhibits should prove to be uniform. The Likiang specimens listed under this race cannot be identified as lichiensis, for they are distinctly too gray and close to pernyi. Three of them are excessively worn dorsad. The race lichiensis may be invalid or there may have been a recent infusion of individuals of the typical race into a part of these mountains, if the surrounding topography renders this a possibility. G. M. 
Allen (1925) noted that his specimens from the Likiang Range were barely distinguishable from griselda, rather than more yellowish olivaceous than flavior, as stated by the describer of lichiensis, so it is evident that his specimens are also of the grayer type which I have referred to pernyi.

\section{DREMOMYS PERNYI CALIDIOR Thomas}

Dremomys pernyi calidior Thomas, Ann, Mag. Nat. Hist., ser. 8, vol. 17, 1916, p. 394 (Kuatun, Fukien, China).

Specimens.-Two from Kuatun, Fukien.

The bases of the ear patches of these topotypes can hardly be described as white, as mentioned by Thomas. In fact they are but little lighter than the ochraceous color upon the tips of the hairs.

\section{DREMOMYS PERNYI FLAVIOR G. M. Allen}

Dremomys perñyi flavior G. M. Allen, Proc. Biol. Soc. Wash., vol. 25, 1912, p. 178 (Mentsz, Yunnan, China).

Specimens.-Eight from Hwangtsaopa, Kweichow.

These are all September specimens. In addition to the buffy underparts, most strongly marked upon the throat, chest, and in the inguinal region, the cheeks have a strong undertone of ochraceous, as has the undertail. The ruddy anal area is situated well caudad and extends markedly down the medial side of the thighs. The skins seem to be not quite typical and are from fairly midway between the type localities of modestus and favior; but their size, as well as the character of pelage, places them with the latter race.

\section{DREMOMYS PERNYI GRISELDA Thomas}

Dremomys pernyi griselda Thomas, Ann. Mag. Nat. Hist., ser. 8, vol. 17, 1916, p. 392 (Nagchuka, Szechwan, China).

Specimen.-One from Damala Pass, Szechwan.

The clear gray of the undertail is characteristic of this race.

\section{DREMOMYS PERNYI LICHIENSIS Thomas}

Dremomys pernyi lichiensis Thomas, Ann. Mag. Nat. Hist., ser. 9, vol. 10, 1922, p. 403 (Likiang Range, Yunnan, China).

Specimens.-Three from Likiang Mountains, Yunnan.

Variation among the squirrels of this genus occurring in northwestern Yunnan has never been well understood. Several mistakes in identification are known to have been made in the past and undoubtedly others remain undetected. For one thing it is felt that seasonal variation and possibly age differences are not well understood. Under ordinary circumstances it would be considered that 
this name should be placed in synonymy, for two subspecies of one species are herein assigned to this one mountain range-a procedure which seldom conforms to good usage. But in other instances the evidence is rather conclusive that two subspecies may occur on different slopes of this mountain range. Because there is so much variation among the Likiang Dremomys, then, the race lichiensis may possibly prove to be untenable. If it is valid, however, then these two specimens are the only ones among those at hand that may be assigned to it. They were taken in April and July and are very buffy, with the anal patch of large extent and the postaricular areas conspicuous.

\section{DREMOMYS RUFIGENIS LENTUS A. B. Howell}

Dremomys rufigenis lentus A. B. Howell, Journ. Wash. Acad. Sci., vol. 17, 1927 , p. 80 (near Wenchuanshein, Szechwan, China, at 6,000 feet altitude).

Specimen.-One, the type.

This race is based upon the uniformity of coloration of the flanks, back and cheeks. The rufous of the underparts is confined to the chin and upper lips, anal region, and faintly along the inner margin of the hind legs. The postauricular spots are buffy.

\section{Genus SCIUROTAMIAS Miller}

\section{SCIUROTAMIAS DAVIDIANUS DAVIDIANUS (Milne-Edwards)}

Sciurus davidiamus Milne-Edwards, Rev. Zool., vol. 19, 1867, p. 190 (Peking, Chihli, China).

Specimens.-Twenty seven: Hsinlungshan, 2, Wulingshan, 2, Chingwangtao, 11, and 15 miles west of Peking, 1-the foregoing in Chihli; mountains northwest of Taiyuanfu, 9 , and mountains 10 miles south of Wutai, Shansi, 1; and 15 miles east of Yenanfu, Shensi, 1.

The Shensi example varies toward owsteni.

\section{SCIURotamias DaVidianUs owsteni J. A. Allen}

Sciurotamias owsteni J. A. Allen, Bull. Amer. Mus. Nat. Hist., vol. 26, 1909, p. 428 (Taipeishan, Shensi, China).

Specimens.-Fourteen : Luitsuen, near Sianfu, 4; near Chingchienshein, 2 ; and Taipeishan district, 80 miles west-southwest of Sianfu, 3 - the foregoing in Shensi : the following in the province of Szechwan-Wenchuen, 1; Sungpan, 2; and Ludinchiao, 1. And one from Hwangtsaopa, Kweichow.

One from near Chingchienshein varies toward typical davidianus. Than the latter this race is a trifle larger with brighter, browner back, tail and feet, more richly colored underparts, and there is a strong suggestion of white striping extending caudad from the ears. 


\section{Genus EUTAMIAS Trouessart}

\section{EUTAMias ASIATICUS ALBOgULARIS J. A. Allen}

Eutamias albogularis J. A. Allen, Bull. Amer. Mus. Nat. Hist., vol. 26, 1909, p. 429 (Taipeishan, Shensi, China).

Specimens.-Two from Kansu, probably from the neighborhood of Choni.

These are juveniles but are easily distinguishable from intercessor of the same province by the distinctness of the five dark dorsal stripes and by the buffy, almost yellow underparts.

\section{EUTAMIAS ASIATICUS INTERCESSOR Thomas}

Eutamias asiaticus intercessor Thомas, Abst. Proc. Zool. Soc. London, 1908, p. 44 (Ningwufu, Shensi, China).

Specimens.-Twenty: Mountains 30 miles west of Kueihuacheng, Shansi, 1; Lanchow, 10; and Chingningchow, Kansu, 9.

One of the specimens from Chingningchow was compared by Miller with the type and pronounced entirely typical. Hence there is no question of the identity of the present series. This race was said by Thomas to be intermediate in general tone between senescens and ordinalis but I find it duller and darker even than the former. The rump is less bright, head grayer, stripes blacker, and foot larger. The Kueihuacheng specimens are tentatively placed here as they more closely resemble this form than any other. The shoulders are very gray, face markings bright, and the lighter dorsal stripes particularly whitish.

\section{EUTAMIAS ASIATICUS ORDINALIS Thomas}

Eutamias asiaticus ordinalis Thomas, Abst. Proc. Zool. Soc. London, 1908, p. 44 (Yulinfu, Shansi, China).

Specimens.-Seventeen: 50 miles northwest of Sianfu, 1, and Yulinfu, Shensi, 1; 30 miles west of Linghsien, 1, and from 18 to 95 miles west of Taiyuanfu, Shansi, 13; and the vicinity of Chingningchow, Kansu, 1.

This is a very pale race. The single specimen from Kansu is indistinguishable from the topotype, although other specimens from this vicinity are unquestionably intercessor. Most of the Shansi examples are not typical and the only way in which they can be distinguished from senescens is by the grayer nuchal region and paler, less rufous sides. In his notes Mr. Sowerby writes that in Shansi and Shensi these active creatures are to be found everywhere, living as they do in woods, in loess gullies and even in stony river beds. They depend mostly on the cultivated fields for their food but he has found their pouches filled with the seeds of grass 
and various other plants. In some places the wild jujube affords them a plentiful autumn harvest.

\section{EUTAMIAS ASIATICUS ORIENTALIS (Bonhote)}

Tamias orientalis Bonноте, Ann. Mag. Nat. Hist., ser. 7, vol. 4, 1899, p. 385 (Upper Ussuri River, Siberia).

Specimens.-Twenty-four: 120 miles up the Yalu River, in Korea, 1 , and the following localities in Manchuria -60 miles southwest of Kirin, 3; 120 miles northeast of Sansing, 10; 20 to 35 miles southsoutheast of Chaoyangchen, 5; Imienpo, 4; and 180 miles up the Yalu River, 1.

Practically all of the individuals listed may be regarded as fairly typical save that a few are inclined to have the rump duller. The Korea specimen is unusually bright, especially upon the head, and the other Yalu River skin is in much worn pelage, showing practisally no bright coloring whatever.

Thomas (1908) considered that the races of $E$. asiaticus and $E$. senescens belong to a single species, while G. M. Allen (1925) considered them distinct. Certainly typical specimens of true asiaticus and senescens are very different looking, but some individuals of orientalis and intercessor, although differing in tone, have so much in common as regards character of striping, that $\mathrm{I}$ am inclined to agree with Thomas.

\section{EUTAMIAS ASIATICUS SENESCENS Miller}

Eutamias senescens Mrruer, Proc. Acad. Nat. Sci. Phila., 1898, p. 349 (Western Hills, 15 miles west of Peking, Chihli, China).

Specimens.-Eight from Chihli: The type; Chingwangtao, 1; and 65 to 75 miles northeast of Peking, 6.

\section{EUTAMIAS ASIATICUS UMbrosus A. B. Howell}

Eutamias asiaticus umbrosus A. B. Hower., Journ. Wash. Acad. Sci., vol. 17, 1927, p. 80 (140 miles south of Lanchowfu=vicinity of Archuen, Minshan Mountains, Kansu, China).

Specimens.-Four: From the type locality (the type) and vicinity, 2 ; and Sungpan, Szechwan, 2.

This is a dark-colored chipmunk differing from intercessor, its nearest ally, in the absence of gray hairs throughout the darker areas of the head and shoulders. The coloration of the head is darker and duller and the gray tips to the hairs upon the upper side of the tail practically hide any ochraceous markings.

\section{Genus TAMIOPS J. A. Allen}

\section{TAMIOPS MACCLELLANDI FORRESTI Thomas}

Tamiops maritimus forresti Tномаs, Ann. Mag. Nat. Hist., ser. 9, vol. 5, 1920, p. 305 (Likiang Mountains, Yunnan, China). 
Specimens.-Two from Yunnan: Yangtze Valley at 10,000 feet altitude, 1 ; and the north slope of the Likiang Range, 1.

Although the Likiang example was taken during the last of April it has the three dark stripes more usual in summer skins of this genus. The precise locality of capture for the second specimen is unknown, but except for its worn pelage with but the one dark stripe characteristic of late winter, it matches the Likiang skin so well that I have no hesitancy in placing the two together. This is evidently the most olivaceous of all the west China races of Tamiops.

\section{TAMIOPS MACCLELLANDI HAINANUS J. A. Allen}

Tamiops macclellandi hainanus J. A. Allen, Bull. Amer. Mus. Nat. Hist., vol. 22, 1906, p. 476 (Leimuimon Hainan, China).

Specimen.-One from Kachek, Hainan.

This skin is without measurements, and the skull is precisely intermediate in size between hainanus and riudoni as listed by Allen. Comparison with typical skins, however, shows that this example belongs to the former race.

\section{TAMIOPS MACCLELLANDI MARITIMUS (Bonhote)}

Sciurus macclellandi maritimus Bonноте, Ann. Mag. Nat. Hist., ser. 7, vol. 5, 1900, p. 51 (Foochow, Fukien, China).

Specimens.-Six from 70 miles southwest of Yenpingfu, Fukien.

These specimens were secured in late November and December and although the difference in coloration from monticola is not greater than is the range of seasonal variation within this group it is of a different quality. The characters exhibited are those ascribed to this race and while they were taken only 70 miles from the locality of capture of the monticola series they were secured at a considerably lower elevation.

\section{TAMIOPS MACCLELLANDI MONTICOLA (Bonhote)}

Sciurus macclellandi monticola Bonноте, Ann. Mag. Nat. Hist., ser. 7, vol. 5, 1900, p. 52 (Chingfengling, Fukien, China).

Specimens.-Seven from near Yenpingfu, Fukien.

These examples were taken in April and the pelage is full, unworn, and of a rather warm tone.

\section{TAMIOPS MACCLELLANDI RUSSEOLUS Jacobi}

Tamiops macclellandi russeolus JACOBI, Abhandl. Ber. Bus. Tierk. Volkerk. Dresden, vol. 16, 1923, p. 11 (Tsalila near Atenstze, southeast Tibet).

Specimens.-Twelve: Tsarong, Tibet, 1; Sila Mountains, 1, and Hofuping Mountains, Yunnan, 10.

The disposition of this material is unsatisfactory and admittedly makeshift. In the first place Jacobi's description is not particularly 
illuminating, but his character of the shoulders and lower portion of the back being suffused with tawny-ochraceous fits some of my specimens. All of these skins, possibly with the exception of two, were taken in November, and yet the variation is so marked that extremes might be presumed to represent two well-marked races. There are skins, however, showing merging of characters to different degrees, and sufficient is not yet known regarding the seasonal and age variation of the Tamiops to make me willing to describe a new race based upon any of these specimens. In the brighter examples the dorsum shows much ochraceous tawny, the more lateral pale stripes are strongly ochraceous, and there is but a single dark stripe, which is very short. At the other extreme is a grayish tone of pelage, but with the head as ochraceous as in the opposite "phase" of pelage. These have three dark dorsal stripes that are almost black, and the lateral light stripes are buffy, sharply marked, and very broad.

\section{TAMIOPS MACCLELLANDI SWINHOEI (Milne-Edwards)}

Sciurus macclellandi swinhoei Milne-Edwards, Rech. Mamm., 1874, p. 308 (Muping, Szechwan, China).

Specimens.-Two from Szechwan: Wenchwan, 1, and Washan, 1. These summer skins, with the three black dorsal stripes normal to the pelage of this season, are quite typical, and the paler stripes are much more strongly ochraceous than in any other race.

\section{TAMIOPS CLARKEI Thomas}

Tamiops clarkei Thomas, Ann. Mag. Nat. Hist., ser. 9, vol. 5, 1920, p. 304 (Yangtze Valley, northern Yunnan, China).

Specimen.-One from 8,000 feet upon the east slope of the Likiang Mountains, Yangtze Gorge, Yunnan.

This specimen is very distinctive. There is no date of capture but the dark dorsal stripes are sharply contrasting and there is an additional pair laterally that are almost as dark as the others. The tips of the caudal hairs are whitish, rather than ochraceous, and the subauricular stripes are pure white.

\section{TAMIOPS VESTITUS Miller}

Tamiops vestitus Miller, Proc. Biol. Soc. Wash., vol. 28, 1915, p. 115 (65 miles northeast of Peking, Chihli, China).

Specimens.-Fourteen from Chihli : 80 miles east of Peking (Eastern Tombs), 2; and Hsinglungshan, 65 miles northeast of Peking, 12 (including the type).

This form is so distinct that I regard it as very doubtful whether it intergrades with any race of macclellandi. Winter skins have the lateral stripes dull and almost like the fianks, whereas in summer 
skins these lines are almost black. This seasonal variation is, of course, usual in most if not all members of this genus.

\section{Genus SCIURUS Linnaeus}

I do not consider that Callosciurus is sufficiently well marked to merit full generic standing, and so include the bay-bellied squirrels of China under the genus Sciurus.

\section{SCIURUS ERYTHRAEUS BONHOTEI Robinson and Wroughton}

Sciurus castaneoventris bonhotei Robinson and Wrovghton, Journ. Fed. Malay States Mus., vol. 4, 1911, p. 234 (Szechwan).

Specimens.--Nine from Szechwan: Ludin, 1; Mount Omei, 5; Suifu, 1; and Kiating, 2.

These skins are not uniform or precisely typical of this race for there is a strong tendency toward black toes; but they are nearer this than any other form. The ears are like the back, there is a suggestion of barring upon the tail, and the bay color of the underparts is dark in tone.

\section{SCIURUS ERYTHRAEUS CASTANEOVENTRIS GraY}

Sciurus castaneoventris Gray, Ann. Mag. Nat. Hist., ser. 1, vol. 10, 1842, p. 263 (China).

Specimens.-Four: Kachek, Hainan, 1, and 1 each from Kushan, Peiliang, and Foochow, Fukien.

These skins are quite typical of this race as now understood. Thomas considers that Hainan examples, named insularis by $\mathrm{J}$. A. Allen, are indistinguishable from mainland specimens.

\section{SCIURUS ERYTHRAEUS GLOVERI (Thomas)}

Callosciurus castaneoventris gloveri Thomas, Journ. Bombay Nat. Hist. Soc., vol. 27, 1921, p. 502 (Nagehuka, Szechwan, China).

Specimens.-Two from Szechwan: Nagchuka, 1, and Mili, 1.

The single topotype is paler above than any specimen of this group at hand, the ears are strongly ochraceous, the toes are not black, and the intense rufous of the underparts, including the throat, is in sharp contrast to the gray of the chin. The dark zones of the caudal hairs do not form noticeable blackish tail bars and the tail becomes strongly ochraceous toward the tip. On the whole the Mili specimen is closest to this form but it exhibits an interesting variation showing the influence of other characters, as blackish toes, more ochraceous dorsum, and grayer, lightly banded tail.

\section{SCIURUS ERYTHRAEUS GORDONI Anderson}

Sciurus gordoni Anderson, Proc. Zool. Soc. London, 1871, p. 140 (Bahmo, eastern Burma). 
Specimens.-Two from Yunnan; Chuchi, 1, and Linchiafu, 1.

Typical gordoni is known to vary to an unusual amount, but there is only one specimen from the type locality available for comparison-a light individual with pale underparts. The Chuchi example is very different, the dorsal coloration, especially of the tail, being very much browner as well as darker, and the belly a more intense shade of bay. It has, however, a midventral stripe of the same color as the back and on the whole had better be referred to gordoni. The midventral line is almost obliterated in the Linchiafu skin but it is otherwise similar to the one from Chuchi.

\section{SCIURUS ERYTHRAEUS HAEMOBAPHES G. M. Allen}

Sciurus erythraeus haemobaphes G. M. Allen, Proc. Biol. Soc. Wash., vol. 25, 1912, p. 177 (Chihping= Shihping, Yunnan, China) .

Specimens.-Three from the Hofuping Mountains, Mekong Valley, Yunnan.

It is with considerable hesitancy that these squirrels, from so far northwest of the type locality of haemobaphes, are assigned to this race. They certainly should not be presumed to be entirely typical but every character of this form is present, though modified to some extent by michianus influence. Presumably squirrels of the haemobaphes type have entered the region of northwestern Yunnan by way of the Mekong Valley. It may be mentioned that this was first described as a small race but the given condylobasilar length of 48 $\mathrm{mm}$., equal to a total length of about 55 , is above the average of the Chinese squirrels of this group.

\section{SCIURUS ERYTHRAEUS MICHIANUS Robinson and Wroughton}

Sciurus castaneoventris michianus Robinson and Wroughton, Journ. Fed. Malay States Mus., vol. 4, 1911, p. 234 (Likiang, Yunnan, China).

Specimens.-Six from the Likiang plain, Yunnan.

These seem to be fairly typical except for the fact that there is a suggestion of blackness upon the toes.

\section{SCIURUS ERYTHRAEUS STYANI Thomas}

Sciurus styani Thомаs, Ann. Mag. Nat. Hist., ser. 6, vol. 13, 1894, p. 363 (probably Kahing, Kiangsu, China).

Specimen.-One from Kiukiang, Kiangsu.

This seems to be a perfectly typical specimen, with very pale underparts.

\section{SCIURUS VULGARIS CHIHLIENSIS Sowerby}

Sciurus vulgaris chihliensis Sowerbi, Ann. Mag. Nat. Hist., ser. 9, vol. 7, 1921, p. 253 (Wulingshan, 75 miles northeast of Peking, Chihli, China).

Specimen.-One-the type. 


\section{SCIURUS VULGARIS COREAE Sowerby}

Sciurus vulgaris coreae SowerBy, Ann. Mag. Nat. Hist., ser. 9, vol. 7, 1921, p. 252 (Kaloguai, 55 miles northeast of Seoul, Korea).

Specimens.-Four from Seoul, Korea.

These are summer and early fall examples.

\section{SCIURUS VULGARIS MANTCHURICUS Thomas}

Sciurus vulgaris mantchuricus Thомаs, Ann. Mag. Nat. Hist., ser. 8, vol. 4, 1909, p. 501 (Khingan Mts., Manchuria).

Specimens.-Four: Urga district, Mongolia, 1; Fengtien, 1, and Imienpo, Manchuria, 2.

The Manchurian skins, taken in June, September, and October, have but little brownish tinge dorsad. That from Mongolia is a winter example and totally without brown. The white of its underparts seems to extend quite to the anus, which it does not do in the Manchurian skins.

\section{SCIURUS CANICEPS CANIGENUS A. B. Howell}

Sciurus caniceps canigenus A. B. HowenL, Journ. Wash. Acad. Sci., vol. 17, 1927, p. 81 (Haiyenhsien, Hangchow Bay, Chekiang, China).

Specimens.-Five from Chekiang: Kangpu near Hangchow, 2 ; and Haiyenhsien, Hangchow Bay, 3 (including the type).

The occurrence of a representative of this species in this part of China is of considerable interest. Average measurements of the above five individuals are, head and body, 198; tail, 143; hind foot, 48.4; ear, 20.7 ; and skull, $50.3 \mathrm{~mm}$.

\section{Genus RATUFA Gray}

RAtUfa gigantea hainana J. A. Allen

Ratufa gigantea hainana J. A. Allen, Bull. Amer. Mus. Nat. Hist., vol. 22, 1906, p. 472 (Cheteriamg, Hainan, China).

The single flat skin with skull at hand is without definite locality but was received from S. F. Light with a small collection of mammals from Hainan only.

\section{Genus TROGOPTERUS Heude}

\section{TROGOPTERUS EDITHAE Thomas}

Trogopterus edithae Thомas, Ann. Mag. Nat. Hist., ser. 9, vol. 11, 1923, p. 658 (Northwest flank of the Likiang Mountains, Yunnan, China).

Specimen.-One from Washan, Szechwan.

This individual, of which the skin and skull are both imperfect, is immature (the hind foot measures $58 \mathrm{~mm}$.) and the teeth are entirely unworn. The first upper tooth is deciduous, as is indicated by the vacuity beneath its root, and is hardly broader (3.3 mm.) 
than the molars, and but little longer (4.5). The tooth pattern is entirely comparable to that given for an animal of this genus by Heude, ${ }^{2}$ that being of a young specimen also. As this is the only representative of the genus in the National collection it was sent to Mr. Thomas, who pronounced it typical of this species.

\section{Genus PETAURISTA Link}

\section{PETAURISTA CLARKEI Thomas}

Petaurista clarkei Thomas, Ann. Mag. Nat. Hist., ser. 9, vol. 10, 1922, p. 396 (Mekong Valley, Yunnan, China).

Specimens.-Three from Tsehchung, Yunnan.

This squirrel has the hairs slaty at base, tipped upon the body with cream, and upon the parachute with rufous. Below the pelage is buffy, darkening to ochraceous on the parachutes. The head is pale gray, the tail tip black, and the feet rufous.

\section{PETAURISTA RUBICUNDUS A. B. Howell}

Petaurista rubicundus A. B. Howell, Journ. Wash. Acad. Sci., vol. 17, 1927, p. 82 (Mapientung, Szechwan, China).

Specimen.-One-the type.

This squirrel has the underparts light but bright rufous, face, chin, sides of neck and feet darker rufous, and hairs of the remainder of the body appearing to be broadly tipped with the same color, although closer inspection shows that the end of the guard hairs are black. The tip of the tail is also black.

\section{Petaurista sulcatus A. B. Howell}

Petaurista sulcatus A. B. HowelL, Journ. Wash. Acad. Sci., vol. 17, 1927, p. 82 (Hsinlungshan, 65 miles northeast of Peking, Chihli, China).

Specimens.-Three from Chihli: Hsinlungshan, 2 (including the type); Eastern Tombs, 1.

This is a squirrel of the xanthotis type of dull coloration but considerably smaller. The maxillary incisors are very broad and each with a well-defined groove.

\section{PETAURISTA XANTHOTIS (Milne-Edwards)}

Pteromys xanthotis Milne-Edwards, Ann. Sci. Nat., Zool., vol. 8, 1867, p. 301 (Tibet).

Specimen.-One from Taochow, Kansu.

This fine flying squirrel is apparently distinct from melanopterus, as discussed in the original description of $P$. sulcatus. It may be mentioned that by "Tibet," Milne-Edwards usually signified a part of the country that is now within the borders of China. 


\section{PETAURISTA YUNNANENSIS (Anderson)}

Pteromys yunnanensis Anderson, Ann. Mag. Nat. Hist., ser. 4, vol. 16, 1875, p. 282 (Zeugyechen, Yunnan, China).

Specimens.-Two from Tsehchung, Yunnan.

In one specimen of this magnificent flying squirrel the white of the underparts is sharply differentiated from the rufous of the under border of the parachute. In the other the transition is gradual and there is a tinge of rufous over most of the underparts.

\section{Genus SCIUROPTERUS F. Cuvier}

\section{SCIUROPTERUS BUECHNERI Satunin}

Sciuropterus buechneri Satunin, Ann. Mus. Zool. Acad. Imp. Sci. St. Petersb., vol. 7, 1902, p. 549 (Tschortentanm, Kansu, China).

Specimens.-Nine from Wutsaishan, Shansi.

Mr. Sowerby found these beautiful little flying squirrels to be an inhabitant of the dense forests that cover the mountains near Wutsai above an altitude of about 7,000 feet: All were brought in by natives, who said that they feed on nuts and pine seeds, as one would expect.

\section{Family MUSCARDINIDAE \\ Genus TYPHLOMYS Milne-Edwards \\ TYPHLOMYS CINEREUS Milne-Edwards}

Typhlomys cinereus Milne-Edwards, Bull. Soc. Philom., vol. 11, 1877, p. 9 (western Fukien, China).

Specimens.-Four from Kuatun, Fukien.

These are practically topotypes of this rare rodent.

\section{Family CRICETIDAE}

\section{Genus CRICETULUS Milne-Edwards}

\section{CRICETULUS ANDERSONI Thomas}

Cricetulus andersoni Thomas, Proc. Zool. Soc. London, 1908, p. 642 (100 miles northwest of Taiyuanfu, Shansi, China).

Specimens.-Twenty-five: Chingningchow, Kansu, 1; Yenanfu, Shensi, 1; and the following from Shansi: 90 miles west, 8 ; 50 miles northwest, 5 ; 20 miles east, 2 ; and 5 miles south of Taiyuanfu, 8 .

Those from northwest of Taiyuanfu are appreciably paler than the ones from west of this locality.

Sowerby found this little hamster distributed all over northern Shansi and Shensi. It was to be met with in any mountainous or hilly country and seemed to be extremely common. They were nearly always caught close to cultivated fields. It would seem that they 
make use of any burrow that they encounter, but they do make holes for themselves and these generally go straight into the ground and are round and smooth. At the mouths of the latter one seldom catches any other rodent.

\section{CRICETULUS GRISEUS GRISEUS (Milne-Edwards)}

Cricetus (Cricetulus) griseus MILNE-Edwards, Rech. Mamm., 1871, p. 133 (Peking, Chihli, China).

Specimens.-Ten: Tientsin, 7, and Tabul, Chihli, 2; and Weihsien, Shantung, 1.

The Tientsin specimens are all in winter pelage and are considerably grayer and less cohraceous than the two summer examples from Tabul.

\section{CRICETULUS GRISEUS FUMATUS Thomas}

Cricetulus griseus fumatus Thомаs, Ann. Mag. Nat. Hist., ser. 8, vol. 4, 1909, p. 503 (Chuchiatai, near Changchun, Kirin, Manchuria).

Specimens.-Three from 120 miles northeast of Sansing, Manchuria.

This is a dark race and very distinct.

\section{CRICETULUS GRISEUS OBSCURUS (Milne-Edwards)}

Cricetus (Cricetulus) 'obscurus MILNE-Edwards, Rech. Mamm., 1871, p. 136 (Saratsi, Shansi, China).

Specimens.--Eight from 20 miles west of Ningwufu, Shansi.

These specimens are not actually paler than comparable winter material of griseus typicus, but they are much more ochraceous.

\section{CRICETULUS TRITON TRITON (de Winton)}

Cricetus (Cricetulus) triton DE Winton, Proc. Zool. Soc. London, 1899, p. 575 (Northern Shantung, China).

Specimens.-Fourteen: Near Tientsin, Chihli, 8; and Weihsien, Shantung, 6 .

These are evidently not quite typical. Most of them have all white feet but in several there is more than a suggestion of duskiness about the ankle, thus approaching fuscipes.

\section{CRICETULUS TRITON COLLINUS G. M. Allen}

Cricetulus triton collinus G. M. Allen, Amer. Mus. Nov., no. 179, 1925, p. 5 (Taipeishan, Tsinglingshan, Shensi, China).

Specimen.-One from the Taipeishan district, 80 miles westsouthwest of Sianfu, Shansi.

This single immature, a virtual topotype of collinus, is appreciably darker than any of the north Shansi specimens at hand. 


\section{CRICETULUS TRITON INCANUS Thomas}

Cricetulus triton incanus Thомаs, Abst. Proc. Zool. Soc. London, 1908, p. 45 (12 miles northwest of Kolanchow, Shansi, China).

Specimens.-Yenanfu, Shensi, 1 ; 5 miles south, $11 ; 20$ miles east, 3 ; and 50 miles northwest of Taiyuanfu, Shansi, 1.

Two of these individuals were compared by G. S. Miller, jr. at the British Museum with the type of incanus and pronounced typical. They are very little if any paler, however, than the Tientsin skins that have been referred to triton typicus.

Sowerby found them rather uncommon, inhabiting either fields or mountainous country. The burrow is usually very round and descends either perpendicularly or at a very sharp angle for some distance. When the farmers were plowing preparatory to planting winter wheat near Taiyuanfu they often turned up live specimens. When brought to bay in the open they would roll over on their backs and defend themselves from this position. They are very destructive to native crops as they lay up large stores of such grains as beans and millet.

\section{CRICETULUS TRITON NESTOR Thomas}

Cricetulus nestor Thomas, Proc. Zool. Soc. London, 1907, p. 466 (Kimhoa. 65 miles northeast of Seoul, Korea).

Specimens.-Twelve: Near Imienpo, 1, and 60 miles southwest of Kirin, Manchuria, 3; 150 miles up the Yalu River, Korea, 7; and 75 miles northeast of Peking, Chihli, 1.

On the basis of its dark coloration I am compelled to list under this race the above juvenile from Chihli. Two of the specimens are considerably larger than the measurements given Mr. Thomas.

\section{Genus CRICETISCUS Thomas}

\section{CRICETISCUS CAMPBELLI (Thomas)}

Cricetulus campbelli Tномаs, Ann. Mag. Nat. Hist., ser. 7, vol. 15, 1905, p. 322 (northern Chihli, China).

Specimens.-Two from Tabul, Chihli.

In the original description the type locality of this species was erroneously stated to be at a spot about 200 miles north of Chihli, a mistake later corrected by the describer.

\section{Genus PHODOPUS Miller}

\section{PHODOPUS BEDFORDIAE (Thomas)}

Cricetulus bedfordiae Thomas, Abst. Proc. Zool. Soc. London, 1908, p. 45 (Yulinfu, Shensi, China).

Specimens.-Twenty-two: Wutsai, Shansi, 1; Yulinfu, Shensi, 21. 


\section{Genus CLETHRIONOMYS Tilesius}

\section{CLETHRIONOMYS RUFOCANUS REGULUS (Thomas)}

Craseomys reguhus Thомas, Proc. Zool. Soc. London, 1906, p. 863 (Mingyong, Seoul, Korea).

Specimens.-Fifty-four: Sungari River, 23, and Imienpo, Manchuria, 23; 150 miles up the Yalu River, 6, and Potaidon, Korea, 2.

There is more individual than geographic variation in the skulls of these specimens. Those from the Yalu River are paler than the Imienpo examples, but this difference may be seasonal.

\section{CLETHRIONOMYS RUFOCANUS SHANSEIUS (Thomas)}

Craseomys shanseius Thomas, Proc. Zool. Soc. London, 1908, p. 643 (100 miles northwest of Taiyuanfu, Shansi, China).

Specimens.-Thirteen from Shansi: 50 miles northwest of Taiyuanfu, 5, and 90 miles west of the same place, $6 ; 30$ miles west of Kueihuacheng, 2.

Sowerby found these red-backed mice most commonly in the vicinity of mossy banks in forests.

\section{Genus MICROTUS Schrank}

MICROTUS (CARYOMYS) INEZ INEZ Thomas

Microtus (Eothenomys) inez Thomas, Abst. Proc. Zool. Soc. London, 1908, p. 45 (Kolanchow, Shansi, China).

Specimen.-One from Yenanfu, Shensi.

\section{MICROTUS (CARYOMYS) INEZ NUX Thomas}

Microtus (Eothenomys) nux Thомas, Abst. Proc. Zool. Soc. London, 1910, p. 26 (Shangchow, Shensi, China).

Specimens.-Three from Shangchow, Shensi.

This is a darker, less brown animal than inez typicus and the relationship of the two is undoubtedly subspecific. Hinton (1926) in his monograph of the voles placed both inez and nux in the synonymy of Evotomys rufocanus shanseius and stated that both of these forms as well as other Caryomys were based upon immature specimens of the local subspecies of Evotomys rufocanus. The three examples listed above were a part of the original series upon which Thomas based his description of $n u x$, and they are conclusively different from the Evotomys, or as now termed, Clethrionomys, of this locality, of any age whatsoever, both the skins and the skulls departing from the latter in a number of important respects.

\section{MICROTUS (EOTHENOMYS) MELANOGASTER MELANOGASTER (Milne-Edwards)}

Arvicola melanogaster Milne-Edwards, Nouv. Arch. Mus., vol. 7, 1871, p. 93 (Muping, Szechwan, China). 
Specimen.-One from just south of Mount Omei, Szechwan.

The skull of this single specimen is closer to the typical race than to mucronatus.

\section{MICROTUS (EOTHENOMYS) MELANOGASTER COLURNUS Thomas}

Microtus (Eothenomys) melanogaster colurnus Thomas, Ann. Mag. Nat. Hist., ser. 8, vol. 7, 1911, p. 209 (Kuatun, Fukien, China).

Specimens.-Seven from the type locality.

One of these topotypes has four inner salient angles to $\mathrm{m}^{3}$, but is otherwise indistinguishable from the rest.

\section{MICROTUS (ANTELIOMYS) CHINENSIS Thomas}

Mierotus chinensis Thомаs, Ann. Mag. Nat. Hist., ser. 6, vol. 8, 1891, p. 117 (Kiatingfu, Szechwan, China).

Specimens.-Five from Washan, Szechwan.

A late October specimen has a striking golden overtone to the dorsum, caused by minute golden tips to the longer hairs. The remainder were taken during July and are in ragged pelage, somewhat darker.

MICROTUS (PHAIOMYS) MANDARINUS MANDARINUS (Milne-Edwards)

Arvicola mandarinus Milne-Edwards, Rech. Mamm., 1871, p. 129 (probably near Saratsi, Shansi, China (see G. M. Allen, 1924)).

Specimens.-Three, from 5 miles south and 50 miles northwest of Taiyuanfu, Shansi.

Sowerby found these voles inhabiting grassy hillsides.

\section{MICROTUS (PHAIOMYS) MANDARINUS JOHANNES Thomas}

Mierotus johannes Thomas, Abst. Proc. Zool. Soc. London, 1910, p. 25 (12 miles northwest of Kolanchow, Shansi).

Specimens.-Five from Wutsai, 20 miles west of Ningwufu, Shansi.

These specimens were compared by Mr. Miller with the type in the British Museum. Sowerby found this race to be an inhabitant of open fields. In his notes he mentioned that the range of mountains lying between Ningwufu and Taiyuanfu evidently constitute a barrier which separates the ranges of true mandarinus from the paler race of the Ordos type of desert country to the northwest, just as this range marks the southern boundary in this region of the distribution of Phodopus and Dipus.

\section{MICROTUS (PHAIOMYS) PULLUS Miller}

Microtus pullus Mrlter, Proc. Biol. Soc. Wash., vol. 24, 1911, p. 53 (Chiaochengshan, 90 miles west of Taiyuanfu, Shensi, China).

Specimens.-Three (including the type) from the type locality. It is probable that this animal is but a darker subspecies of mandarinus, but the material available is not adequate to establish this 
point. Sowerby found it to inhabit the open, grassy hillsides clear to their tops, at 9,500 feet.

\section{MICROTUS (PHAIOMYS) BRANDTI (Radde)}

Arvicola brandti RADde, Mél. Biol. Acad. St. Petersb., vol. 3, 1861, p. 683 (Mongolia).

Specimens.-Six (including the type of $M$. warringtoni) from Tabul, Chihli.

With access to a series of virtual topotypes of brandti, G. M. Allen (1924) found that the size of the latter is fully as great as of the specimens upon which G. S. Miller based his description of $M$. warringtoni. As size was the only racial character ascribed to the latter, I follow Allen's example and list all these specimens under the name brandti.

\section{MICROTUS (NEODON) IRENE Thomas}

Microtus irene Thomas, Abst. Proc. Zool. Soc. London, 1911, p. 5 (Tatsienlu, Szechwan, China).

Specimens.-Two from Szechwan; Shuowlow, 1, and 10 miles south of Tatsienlu, 1.

Although these specimens differ from one another in several respects, they are both assigned to this species for the present.

\section{MICROTUS (STENOCRANIUS) ANGUSTUS Thomas}

Microtus angustus Thомas, Proc. Zool. Soc. London, 1908, p. 108 (about 100 miles northwest of Kalgan, Chihli, China).

Specimens.-Four from Tabul, Chihli.

These are virtual topotypes.

\section{MICROTUS CALAMORUM CALAMORUM Thomas}

Microtus calamorum Tномаs, Ann. Mag. Nat. Hist., ser. 7, vol. 10, 1902, p. 167 (near Nanking, Kiangsu, China).

Specimens.-Twenty from Yochow, Hunan.

There is some resemblance of this large vole to $M$. pelliceus, as already pointed out by Thomas, but the relationship is hardly nearer than specific. Hoy found many nestling young in early June, and it is gathered from his field catalog that this species inhabits fairly dry fields as well as the rushy growths of swampy areas.

\section{MICROTUS CALAMORUM SUPERUS Thomas}

Microtus calamorum superus Thомаs, Abst. Proc. Zool. Soc. London, 1911, p. 27 (30 miles south of Fenghsiangfu, Shensi, China).

Specimen.-One skull only from Taipingsha, Shensi. 
MICROTUS PELLICEUS Thomas

Microtus pelliceus Thomas, Ann. Mag. Nat. Hist., ser. 8, vol. 7, 1911, p. 383 (Ussuri River, Siberia).

Specimens.-Twenty-nine from the Sungari River, 60 miles southwest of Kirin, Manchuria.

In this species the incisors are much longer and project farther than in $M$. calamorum.

\section{Family RHIZOMYIDAE}

\section{Genus RHIZOMYS Gray}

\section{RHIZOMYS DAVIDI Thomas}

Rhizomys davidi Thomas, Abst. Proc. Zool. Soc. London, No. 90, 1911, p. 5 (Kuatun, Fukien, China).

\section{Specimens.-Three from Yenpingfu, Fukien.}

The skulls of the two largest individuals show some differences and it is by no means impossible that the largest and smallest specimens may ultimately prove to be sinensis, but in the absence of undoubted representatives of the latter race, and in view of the fact that they are all from the same place, it is certainly wiser to refer these specimens to davidi.

\section{RHIZOMYS VESTITUS Milne-Edwards}

Rhizomys vestitus MILNE-Edwards, Nouv. Arch. Mus., 1871, p. 93 (Muping, Szechwan, China).

Specimens.-Five from Szechwan: Wenchwan, 3, and Wanhsien, 2. The condylobasilar measurement of some of these skulls is larger (74 mm.) than that given by the describer for vestitus, but the resemblance seems to be with this form rather than $R$. wardi.

\section{Family SPALACIDAE}

\section{Genus MYOSPALAX Laxmann}

The four forms of this genus at hand are certainly not all distinct species, but the binomial should be used for them until a better understanding of the Asiatic molerats has been gained.

\section{MYOSPALAX CANSUS (Lyon)}

Myotalpa cansus Lyon, Smiths. Misc. Coll., vol. 50, 1907, p. 134 (Taochow, Kansu, China).

Specimens.-Twenty-one: Yenanfu, 1 and Yulinfu, Shensi, 5; and the following from Kansu; 15 miles southeast of Choni, 1; 15 miles northeast of Chengning, 8; Taochow, 1 (the type); 30 miles south of Lanchow, 4; and near Archuen, Minshan Mountains, 1. 
The type of $M$. cansus is male and not female as at first recorded. On the basis of the present material I can not recognize the subspecies shenseius even though topotypes are at hand. The difference in coloration is not sufficient to constitute a tenable character and the length of the maxillary tooth row does not prove to be longer in the Shensi skulls. The color of the four specimens from south of Lanchow is puzzling in that it is practically entirely gray, and the skull of at least one shows some variation; but they are all rather immature and no other disposition can be made of them at present.

\section{MYOSPALAX FONTANUS Thomas}

Myospalax fontanus Thomas, Ann. Mag. Nat. Hist., ser. 8, vol. 9, 1912, p. 93 (Ningwufu, Shansi, China).

Specimens.-Thirteen from Shansi as follows: 20 miles west of Ningwufu, $9 ; 10$ miles south of Wutsai, 1 ; and 90 miles west of Taiyuanfu, 3 .

The three specimens from west of Taiyuanfu are not appreciably different from the virtual topotypes of this large, rather pale form. As is $M$. fontanieri the second nail of the manus is as long as the third. All Sowerby ever saw were dug up by natives while working in their fields, or had been flooded out by irrigation. They are remarkable diggers and he once watched one work its way with astonishing rapidity into the packed ground of a Chinese courtyard. They are clumsy but can get up a fair speed. They dislike light intensely and always try to hide away in some dark corner. When feeding they hold the food down with their forefeet.

\section{MYOSPALAX ROTHSCHILDI Thomas}

Myospalax rothschildi Thomas, Ann. Mag. Nat. Hist., ser. 8, vol. 8, 1911, p. 122 (40 miles southeast of Taochow, Kansu, China).

Specimens.-Five skulls and four skins from Taochow, Kansu.

Although all of these specimens are immature I have no hesitation in assigning them to this distinct species, for not only has the pelage a soft quality and distinctive silvery sheen, but the skull characters of shortness of molar rows and two inner reentrant angles of $\mathrm{m}^{3}$ are shown to good advantage. Additional items of interest are the shortness and hairiness of the tail, relative width of the anterior nasals, slight development of the infraorbital septem of the maxilla, medial palatal spine, form of the hamular processes, and paleness of the incisors.

\section{MYOSPALAX SMITHII Thomas}

Myospalax smithii Thomas, Ann. Mag. Nat. Hist., ser. 8, vol. 8, 1911, p. 720 (30 miles southeast of Taochow, Kansu, China).

Specimens.-Two from Kansu: 30 miles east-southeast of Lanchow, 1 ; and "probably Choni," 1. 
Although not adult the last-mentioned specimen is indubitably assignable to this species on the characters of temporal fossae, interorbital, and third upper molar. An additional detail of importance is the basioccipital, which extends farther ventrad than any part of the bullae. Unfortunately the second specimen is still younger. Although belonging to this group it is considerably different, for the pelage is of a delicate maltese gray with no trace of buffy or brown, the infraorbital formina are very small, the basioccipital higher in respect to the bullae, and the inner reentrant angles of the molars are deeper.

The occurrence of so many forms of this genus in the neighborhood of Taochow is very remarkable, but they have trustworthy characters and there is no reason for doubting their validity.

\section{Family MURIDAE}

\section{Genus MERIONES Illiger}

\section{MERIONES PSAMMOPHILUS (Milne-Edwards)}

Gerbillus psammophilus MILNE-EDwards, Rech. Mamm., 1871, p. 144 (Mongolia).

Specimens.-CTwenty-one: Yulinfu, 2, and Yenanfu, Shensi, 6; 5 miles south, 6 , and 20 miles northwest of Taiyuanfu, 2 , and 20 miles west of Ningwufu, Shansi, 5 .

The Shensi examples average paler and more ochraceous than those from Shansi and it is a question whether the two lots should not be separated. The claws are white, hairs of the underparts almost lacking ochraceous bases, and bullae at times touching the zygomatic arches; but the bullae are so little larger than those of unguiculatus that this is a poor character for differentiation. While Mr. Sowerby was in the Ordos Desert he frequently had opportunity for watching these lively creatures playing about the mouths of their burrows in broad daylight, while elsewhere he has never seen them during the day. They are largely colonial.

\section{MERIONES UNGUICULATUS (Milne-Edwards)}

Gerbillus unguiculatus MrLne-Edwakds, Ann. Sci. Nat., vol. 7, 1867, p. 377 (Mongolia).

Specimens.-Two from Tabul, Chihli.

The claws of this species are black, belly hairs plumbeous at base and with the suggestion of a buffy overwash, and the bullae never touch the zygomatic arches. 


\section{Genus RHOMBOMYS Wagner}

\section{RHOMBOMYS OPIMUS NIGRESCENS (Satunin)}

Gerbillus opimus nigrescens SAtunin, Ann. Mus. Zool. Acad. Imp. Sci. St. Petersb., vol. 7, 1903, p. 560 (Oroknor, central Mongolia).

Specimens.-Nine from 45 to 105 miles northwest of Ninghsia, Kansu.

The validity of this race has not definitely been established and I have not the material to settle the question, but these specimens fit the description admirably.

\section{Genus APODEMUS Kaup}

\section{APODEMUS AGRARIUS COREAE Thomas}

Apodemus agrarius coreae Thомаs, Proc. Zool. Soc. London, 1908, p. 8 (Mingyong, 110 miles southeast of Seoul, Korea).

Specimens.-Five from 65 to 75 miles northeast of Peking, Chihli.

These are not greatly different from $A . g$. mantchuricus but average duller, with black stripe narrower.

\section{APODEMUS AGRARIUS MANTCHURICUS (Thomas)}

Mus agrarius mantchuricus Thomas, Proc. Zool. Soc. London, 1898, p. 774 (Manchuria).

Specimens.-Forty-four from Manchuria: 60 miles southwest of Kirin, 21; 120 miles northeast of Sansing, 6; 180 miles up the Yalu River, 2; Fengtien, 2; and Imienpo, 13.

It is by no means certain that the Yalu River examples should not be called coreae.

\section{APODEMUS AGRARIUS NINGPOENSIS (Swinhoe)}

Mus ningpoensis Swinhoe, Proc. Zool. Soc. London, 1870, p. 637 (Ningpo, Chekiang, China).

Specimens.-Forty-eight: Yochow, Hunan, 37; Taiping, Anhwei, 4; Nanking, 5; Chinkiang, 1; and Shanghai, Kiangsu, 1.

In typical immatures there is quite a strong black dorsal stripe, but not to the extent occurring in true agrarius. In the Anhwei adults, however, there is but the faintest indication of this stripe, while in the Hunan examples it is a bit better defined, though still faint in all but two. Coloration is both pale and dull, with pelage short and having less of the grayish ticking exhibited by pallidior.

APODEMUS AGRARIUS PALLIDIOR (Thomas)

Apodemus agrarius pallidior Thomas, Proc. Zool. Soc. London, 1908, p. 7 (Chefoo, Shantung, China).

Specimens.-Eight: Near Tientsin, Chihli, 2; 15 miles south of Sianfu, 3, and Yenanfu, Shensi, 3. 
This is a paler, sandier race with fine black stripe. The two specimens from Tientsin are excessively pale and gray, and were taken during January.

\section{APODEMUS SPECIOSUS PENINSULAE (Thomas)}

Micromys speciosus peninsulae Thomas, Proc. Zool. Soc. London, 1906, p. 862 (Mingyong, 110 miles southeast of Seoul, Korea).

Specimens.-Eighty-seven: Fengtien, 2, Imienpo, 20, and 60 miles southwest of Kirin, Manchuria, 11; 150 miles up the Yalu River, 3, and Potaidon, Korea, 2; 65 to 75 miles northeast of Peking, Chihli, 12 ; 18 to 90 miles west of Taiyuanfu, 9, 20 miles east of Taiyuanfu, 11, and 30 miles west of Kueihuacheng, Shansi, 5; Taipeishan district, 2, 12 miles south of Yenanfu, 4, 15 miles west of Sianfu, 4, and 80 miles west southwest of Sianfu, Shensi, 2; and 15 miles south of Lanchow, Kansu, 1.

Included in the above list is the material upon which $A$. praetor was based. The type of this is a phenomenally large specimen such as is encountered occasionally in almost all groups of rodents. No other individual of this praetor series is as large as the measurements given by Thomas for peninsulae. The darker, less yellowish coloration ascribed to praetor is seasonal and is a character of the short, summer coat, which, however, may be retained until October. No winter or spring specimen has this type of coloration but at these seasons they are more ruddy. The Chihli series, also in the short, dull, summer coat, have tails that are usually shorter than the head and body. In Shansi and Shensi Sowerby found these mice in almost all wooded or brushy country.

\section{APODEMUS DRACO (Barrett-Hamilton)}

Mus sylvaticus draco Barrett-Hamilton, Proc. Zool. Soc. London, 1900, p. 418 (Kuatun, Fukien, China).

Specimens.-Four from Kuatun, Fukien.

From his papers I judge that Thomas is somewhat doubtful regarding the exact status of draco. I share his uncertainty in this respect and the identification must be provisional. These should certainly be topotypes of draco, but Barrett-Hamilton stated that this is a subspecies of sylvaticus and brighter above than typicus, while the specimens at hand are definitely darker. They are not subspecies of sylvaticus, for there are eight mammae and they have the short incisive foramina of speciosus - not the long ones of sylvaticus. Thomas mentioned that draco has eight mammae but stated nothing further anent its systematic position. 
Genus RATTUS G. Fischer

RATTUS RATTUS RATTUS (Linnaeus)

[Mus] rattus Linnaeus, Syst. Nat., ed. 10, 1758, p. 61 (Upsala, Sweden).

Specimen.-One from Futsing, Fukien.

The only specimen of all black rat secured was this juvenile, too young for other characters to be distinguishable. It probably belongs to this race, to be expected anywhere near the coast, although it is not impossible that it may be a melanistic individual of some other form.

\section{RATTUS RATTUS ALEXANDRINUS (Geoffroy)}

Mus alexandrinus Geoffroy, Cat. Mamm. Mus. Hist. Nat. Paris, 1803, p. 192 (Alexandria, Egypt).

Specimen.-One, from 150 miles up the Min River, Fukien.

This example is indistinguishable from selected European skins and this, together with the fact that it was taken by a river whence it could have been transported by boat, obliges me to identify it as of this race. The tail is 142 per cent of the head and body length and the total length of the skull is $40.5 \mathrm{~mm}$. The length of the tail renders it unlikely that it might properly be ascribed to sladeni.

\section{RATTUS RATTUS ExigUUS A. B. Howell}

Rattus rattus exiguus A. B. Howell, Proc. Biol. Soe. Wash., vol. 40, 1927, p. 43 ( 70 miles southwest of Yenpingfu, Fukien, China).

Specimens.- Sixteen, from the following localities in Fukien: 14 from 70 miles southwest of Yenpingfu, at an altitude of 500 feet; one from Foochow; and one in spirits from Kulingsu Island.

This race is readily distinguished from sladeni and alexandrinus by its pale color, small size and short foot, and from the latter at least by the shorter tail. It should be distinguished without trouble from any other rat of eastern China, although I suspect that it has at times been mistaken for humiliatus, which is evidently very rare in collections.

\section{RATTUS HUMILIATUS HUMILIATUS (Milne-Edwards)}

Mus humiliatus Milne-Edwards, Rech. Mamm., 1871, p. 137 (Peking, Chihli, China).

Specimens.-Three: Chinkiang, Kiangsu, 1; and Canton, Kwangtung, 2.

The Kiangsu example is the only one of the above with measurements and its tail is 93 per cent of the head and body length. Very conflicting measurements have been given for this species, but those who have examined the type are evidently in accord that the tail is shorter than the head and body. In manuscript notes on type speci- 
mens in the Paris Museum, G. S. Miller, jr., has said that there are two mounted cotypes of this rat and that the measurements are: head and body, 160 and 150 ; tail 100 and 96 ; and foot, 30 and $33 \mathrm{~mm}$. It is very probable that other Chinese rats have often been misidentified as this, which seems to be exceedingly rare in collections. From $R$. r. alexandrinus its skull is distinguishable only by the fact that in the latter the anterior portion of the nasals are usually abruptly wider, the temporal ridging heavier, and incisive foramina broader; but these details are not always uniform. The best criterion for differentiating the two is the great difference in the length of the tail. Some might therefore conclude that humiliatus should stand as a subspecies $R$. rattus. And it really seems no more distant from alexandrinus than it does from $R$. $r$. exiguus. I am inclined to believe, however, that although related most nearly to the rattus group, humiliatus is specifically distinct and probably would not cross, under normal conditions, with either of the two rats mentioned. Immature skins of humitiatus may be difficult to distinguish from similar specimens of $R$. norvegicus, but in adults the silky pelage of the former is diagnostic.

\section{RATTUS HUMILIATUS INSOLATUS A. B. Howell}

Rattus humiliatus insolatus A. B. Howell, Proc. Biol. Soc. Wash., vol. 40, 1927, p. 44 (near Yenanfu, Shensi, China).

Specimens.-Four from Shensi: Yenanfu, 3 (including the type); and Yulinfu, 1.

This is a rather large and pale race.

\section{RATTUS HUMILIATUS SOWERBYI A. B. Howell}

Rattus humiliatus sowerbyi A. B. HoweLI, Proc. Biol. Soc. Wash., vol. 41, 1928, p. 42 (near Imienpo, north Kirin, Manchuria).

Specimens.-Two, including the type, from the type locality.

This also is a large race, but dark and richly colored and with the sootiness of the face pronounced. Superficially it is not unlike $R$. norvegicus but the softness of the pelage is distinctive, at least in adults.

\section{RATTUS FLAVIPECTUS (Milne-Edwards)}

Mus flavipectus Mrlne-Edwards, Nouv. Arch. Mus. Hist. Nat., 7, 1871, p. 93 (Muping, Szechwan, China).

Specimens.-Forty-three: Foochow, 3; Kuliang, 2; Futsing, 4; near Yenpingfu, 4; and 70 miles southwest of Yenpingfu, Fukien, 1; near Chinkiang, 7, and Shanghai, Kiangsu, 21; Canton, Kwangtung, 1; and Mount Omei, Szechwan, 1.

The dorsal coloration of this series is rather uniform, but several of the older individuals have a very few white hairs scattered over 
the back. Below there is more variation. The majority have a strongly ochraceous overwash but in many the underparts are grayer, this evidently being due to the wearing away of the hair tips. There is invariably some ochraceous about the chest, however. In but three is there a white pectoral area. The brown of the fore feet is not always sufficiently pronounced to be distinguishable if the specimen is at all dirty or greasy. In the Kiangsu skulls the infraorbital laminae of the maxillae average shorter, but their separation on this character alone is hardly justifiable at present.

\section{RATTUS GRISEIPECTUS (Milne-Edwards)}

Mus griseipectus Milne-Edwards, Nouv. Arch. Mus. Hist. Nat., vol. 7, 1871, p. 93 (Szechwan, China).

Specimens.-Four: 70 miles southwest of Yenpingfu, Fukien, 1; and Yochow, Hunan, 3.

The adult from Fukien measures as follows: head and body, 167; tail, 183; and hind foot, 36. The total length of the skull is $44 \mathrm{~mm}$. Two of the Hunan specimens are alcoholics. The third is much brighter than the one from Fukien and correspondingly more nearly resembles humiliatus in appearance, but the size of the skull with large rostrum and long tail is always sufficient to separate the two species. The identification of the two alcoholics is tentative.

\section{RATTUS NORVEGiCUS CARACO (Pallas)}

Mus caraco Pallas, Nov. Spec. Quad. Glir. Ord., 1878, p. 91 (eastern Siberia).

Specimens.-Seventeen from Manchuria: Imienpo, 2, 60 miles southwest of Kirin, 6, and 120 miles northeast of Sansing, 9.

This rat is differentiated from typicus chiefly by its dark color, less decidedly brown.

\section{RATTUS NORVEGICUS SOCER (Miller)}

Epimys norvegicus socer Mrleer, Proc. Biol. Soc. Wash., vol. 27, 1914, p. 90 (Taochow, Kansu, China).

Specimens.-Sixty-eight: Tientsin, 2; Peking, 20; 80 miles east of Peking, 16, 65 to 75 miles northeast of Peking, 7; and Chingwangtao, Chihli, 1; Taochow, 5 (including the type); Lanchow, 2; and Archuen in the Minshan Mountains, Kansu, 2; Suifu, Szechwan, 10 ; Canton, Kwangtung, 2; and Amoy Island, Fukien, 1.

The majority of these specimens are distinguishable from an average of north European examples of the brown rat but along the coast and larger rivers of China there is bound to have been an infusion of rats brought in by shipping and the correct identification of all specimens in the case of two such slightly differentiated races is manifestly impossible. The Suifu skins are definitely browner of belly and darker of back, but they were made up from salted pelts and one cannot place reliance in these characters. 


\section{RATTUS CONFUCIANUS CONFUCIANUS (Milne-Edwards)}

Mus confuciamus Mrlne-Edwards, Nouv. Arch. Mus. Hist. Nat., vol. 7, 1871, p. 93 (Muping, Szechwan, China).

Specimens.-Fifty-two: Tatsienlu, 4; Suifu, 6; and Wenchwan, Szechwan, 5; Nanking; 1; and Chinkiang, Kiangsu, 8; Yenpingfu, 19; 70 miles southwest of Yenpingfu, 2; Kuliang, 1; Peiliang, 1; Futsing, 1; and Kuatun, Fukien, 2.

The Szechwan skins were made up from salted pelts and all that can be said of them is that at least most of them are true confucianus, for about those with fragmentary skulls little can be told. One of the Suifu examples differs in being excessively spiny over the shoulders but not upon the rump. The skull is broken to bits, however. It was expected that the Fukien rats of this species would prove to be of the race littoreus Cabrera, but such is not the case, for the color is quite dark, there is very little dusky upon the feet of any of them, and instead of having a short tail this member is quite long. The specimens at hand are rather small for typical confucianus but the measurements for this as given by various investigators are conflicting and I follow G. M. Allen in thus identifying the material from this part of China.

Most of the skins were taken in April and the pelage of these is relatively nonhispid, but those secured in late summer are quite spiny. The feet of the majority are pure white and in very few does the dusky area extend beyond the ankle. The tip of the tail usually shows at least some indication of white above, and in a few the terminal third is entirely white.

Skulls may be distinguished from those of huang by the fact that the temporal ridges hardly ever extend to the interparietal, but they are otherwise very similar indeed. It should be mentioned that in all the older females the rostrum is definitely broader than in any male save one, although it is possible that this may be fortuitous. Two have skulls that are considerably larger than the others but otherwise they are similar. The skins from Kiangsu have feet that average larger $(29 \mathrm{~mm})$. Average measurements of five large specimens from Fukien are: head and body, 132; tail, 179; hind foot, 27 ; and total length of skull, $35.5 \mathrm{~mm}$.

\section{RATTUS CONFUCIANUS CHIHLIENSIS Thomas}

Rattus confucianus chihtiensis Thomas, Ann. Mag. Nat. Hist., ser. 8, vol. 20, 1917, p. 199 ( 65 miles east of Peking, Chihli, China).

Specimens.-Fifteen from Chihli: Chingwangtao, 4 ; and 65 to 75 miles northeast of Peking, 11.

The above north China specimens are virtually topotypes. Three of the Chingwangtao skulls are missing but the skins are assigned 
to this race on the basis of their dusky metapodials. Another character differentiating chilliensis from Fukien confucianus is the slenderness of the rostrum; and the bullae average a shade smaller.

\section{RATTUS CONFUCIANUS LUTICOLOR (Thomas)}

Mus confucianus luticolor Tномаs, Abst. Proc. Zool. Soc. London, 1908, p. 45 (Yenanfu, Shensi, China).

Specimens.-Eighteen: Yenanfu, 7; 15 miles south of Sianfu, Shensi, 3; 50 miles northwest of Taryuanfu, 2; 20 miles east of Taiyuanfu, 5; and 30 miles west of Kweihuating, Shansi, 1.

Two of the specimens from Sianfu are darker and the third much more ruddy than topotypes, and the two former at least probably vary toward the race canorus. Those from east of Taiyuanfu might almost as well be placed with chihliensis. Sowerby found these rats most commonly among the rocks along the sides of the valleys.

\section{RATTUS CONFUCIANUS SACER (Thomas)}

Mus confucianus sacer Thомаs, Proc. Zool. Soc. London, 1908, p. 6 (Chefoo, Shantung, China).

Specimens.-Twenty-two from Hunan; Changsha, 2; Yochow, 20.

I have had no opportunity to examine topotypes of this race, but as I understand sacer it is an illy defined subspecies representing various degrees of intergradation between confucianus and chitiensis, and farther west, luticolor also. These Yochow skins are considerably brighter than true confucianus but darker than huticolor, and are variously intermediate in other ways. It may be noted that Yochow is not in Honan, as mentioned by Allen (1926) but in Hunan, which puts a somewhat different interpretation upon specimens from that locality.

\section{RATTUS HUANG HUANG (Bonhote)}

Mus huang Bonноте, Abst, Proc. Zool. Soc. London, 1905, p. 387 (Kuatun, Fukien, China).

Specimens.-Thirty-nine from Fukien : 70 to 75 miles southwest of Yenpingfu, 31; Yenpingfu, 2; Peiliang, 1; Foochow, 1 ; and Kuatun, 4.

This fine series seems to be perfectly typical, although only the very largest specimens equal the measurements usually given for this species. On the other hand, the smallest adult is considerably larger than the dimensions given for ling. In the series at hand there is comparatively little color variation save what is ascribable purely to wear, but there is much as regards spininess of pelage. The fresh, unworn coat has very few and slender spines but the latter increase in number and size as wear of the hairs progresses, until in very ragged individuals the middle back and rump are covered thickly with them. 
There is little cranial variation also, save to some extent in the shape of the posterior termination of the nasals. Skulls may be told from those of confucianus chiefly by the extension in the former of the temporal ridges as far as the interparietal. The rostrum also averages more slender and the interpterygoid narrower. Average measurements of five large specimens are: Head and body, 135; tail, 190; foot, 28; ear, 19; and length of skull, $35.8 \mathrm{~mm}$.

\section{RATTUS EDWARDSI EDWARDSI (Thomas)}

Mus edwardsi Thомas, Proc. Zool. Soc. London, 1882, p. 587 (western Fukien, China).

Specimens.-Two from Kuatun, Fukien.

These very large rats may be considered topotypical, and their skulls measure 61 and $58 \mathrm{~mm}$. in length.

\section{RATTUS EDWARDSI GIGAS (Satunin)}

Mus gigas Satunin, Ann. Mus. Zool. Acad. Imp. Sci. St. Petersb., vol. 7, 1903, p. 562 (Valley of Chodzigou, near Lunganfu, Szechwan, China).

Specimens.-Two from southwest of Mount Omei, Szechwan.

These two specimens are not distinguishable with certainty from. those of Fukien, but G. M. Allen considers gigas to be a valid race and doubtless with adequate material differences would be readily apparent.

\section{RATTUS LATOUCHEI (Thomas)}

Mus latouchei Thomas, Ann. Mag. Nat. Hist., ser. 6, vol. 20, 1897, y. 13 (Kuatun, Fukien, China).

Specimens.-Three: Mount Omei, Szechwan, 1 ; and 70 miles southwest of Yenpingfu, Fukien, 2.

One of the Fukien examples is but half grown and the dorsal coloration is dark sooty with practically no vestige of brown-a type of juvenal coloration usual in cricetid rats but apparently rare in murids. The head, however, has assumed the adult pelage. The larger specimen measures; head and body, 252; tail, 334; foot, 52; and ear, $35 \mathrm{~mm}$. It shows a head coloration that is typical of the species but the body color is evidently unusually dark, being without white tips to any of the hairs. Most of the skull is broken but there remains sufficient to show the cranial characters of latouchei, consisting chiefly of the large size in connection with the fact that the dentations of the premaxillary-frontal sutures do not extend caudad of the posterior tips of the nasals.

Perhaps the Szechwan specimen should be referred to mackenzii, of which no examples are at hand, but the measurements (hind foot 57 ) are larger than are supposed to occur in that race, and both skin and skull are practically indistinguishable from the Fukien adult. 


\section{Genus MUS Linnaeus}

\section{MUS MUSCULUS MUSCULUS Linnaeus}

[Mus] musculus Lrnnaeus, Syst. Nat., ed. 10, 1758, p. 62 (Sweden).

Specimens.-Twenty-three: Peking, Chihli, 3; Kwantsao, Weichow, 3; Suifu, Szechwan, 9; Nanking, Kiangsu, 4; and 70 miles southwest of Yenpingfu, Fukien, 4.

The Suifu specimens are dirty and misshapen and mostly prepared from salted skins. The Chihli examples are also dirty. The only practicable course has therefore been to refer all dark-bellied Mus to musculus. Instead of being darker than typical musculus, as sinicus was said to be, the material from south China averages lighter.

\section{MUS BACTRIANUS GANSUENSIS Satunin}

Mus [Leggada] gansuensis Satunin, Ann. Mus. Zool. Acad. Imp. Sci. St. Petersb., vol. 7, 1903, p. 564 (Tschortentan, Kansu, China).

Specimens.-Two from 128 to 157 miles west-northwest of Paotouchen, Inner Mongolia, and the following from Kansu; near Ninghsia and up to 60 miles west thereof, 7 ; Lanchow, 1 ; and 25 miles southeast of Sining.

I shall follow the example of G. M. Allen (1927) in placing the races of white-bellied Mus of China under the species bactrianus rather than wagneri as usual; but there are no undoubtedly typical specimens of the former available. This series is very pale, with short tail (about 45 per cent of the total length), and without a buffy throat patch.

\section{MUS BACTRIANUS MONGOLIUM Thomas}

Mus wagneri mongolium Tномаs, Proc. Zool. Soc. London, 1908, p. 106 (100 miles northwest of Kalgan, Mongolia).

Specimens.-Fourteen: 3 from near Taiyuanfu, Shensi, and the following from Chihli: Tabul, 6; 80 miles east of Peking, 3 ; and Tientsin, 2.

The Tabul specimens are virtual topotypes and were compared by G. S. Miller with the typical series at the British Museum. These fourteen skins average much darker than the material from Kansu, which I am justified in considering to represent gansuensis. Hence, I can not agree with G. M. Allen (1927) in placing in synonymy under the latter the name mongolium.

\section{MUS BACTRIANUS MANCHU Thomas}

Mus wagneri manchu Thomas, Ann. Mag. Nat. Hist., ser. 8, vol. 4, 1909, p. 502 (Chuchiatai, near Changehun, Kirin, Manchuria).

Specimens.-Seven from Manchuria: 60 miles southwest of Kirin, 5, and 180 miles up the Yalu River, 2.

This race is considerably darker than mongolium.

$$
21776-29-5
$$




\section{Genus MICROMYS Dehne}

MICROMYS MINUTUS PYGMAEUS (Milne-Edwards)

Mus pygmaeus Mine-Edwards, Rech. Mamm., 1874, p. 291 (Szechwan, China).

Specimens.-Five: Yochow, Hunan, 3; and Nanking, Kiangsu, 2.

The Hunan examples are very ochraceous-especially one of thembut I have in mind the ochraceous tones assumed by certain American Dipodomys living on particular types of alkali soil and prefer to call these specimens as above until more material is available.

\section{Genus VANDELEURIA Gray \\ VANDELEURIA OLERACEA (Bennett)}

Mus oleracea Bennett, Proc. Zool. Soc. London, 1832, p. 121 (Dukhun, India).

Specimen.-One from Yangchiaoshan, Yunnan.

The single representative of this rare genus in the National Museum was caught alive in a nest of grass situated in a bush.

\section{Family ZAPODIDAE}

\section{Genus SICISTA Gray}

\section{SICISTA CONCOLOR (Büchner)}

Sminthus concolor Büchner, Mél. Biol. Acad. St. Petersb., vol. 13, 1892, p. 268 (Mountains of Sining, Kansu, China) .

Specimen.-One from near Imienpo, Manchuria.

This is an immature and there is nothing to do but refer it to this species.

\section{Genus ZAPUS Coues}

\section{ZAPUS SETCHUANUS VICINUS Thomas}

Zapus setchuanus vicinus Thомаs, Ann. Mag. Nat. Hist., ser. 8, vol. 10, 1912, p. 402 (46 miles southeast of Taochow, Kansu, China).

Specimens.-Two from Kansu; Choni, 1, and Archuen, Minshan Mountains, 1.

These two specimens are identified upon geographic grounds as there is no comparative material of this genus at hand. The belly is entirely white but the tail of neither is black above to the tip.

\section{Family DIPODIDAE}

\section{Genus ALLACTAGA F. Cuvier}

\section{ALLACTAGA MONGOLICA ANNULATA (Milne-Edwards)}

Dipus annulatus Mrlne-Edwards, Ann. Sci. Nat., vol. 7, 1867, p. 376 (probably near Peking, Chihli, China).

Specimens.-Two from Chihli: Tabul, 1, and 100 miles west of Lamamiao, 1. 
As no specimens of undoubted mongolica typicus are available I follow the opinion of G. M. Allen (1925) in considering that Chihli examples are separable.

\section{ALLACTAGA MONGOLICA LONGIOR Miller}

Allacataga mongolica longior MrLler, Proc. Biol. Soc. Wash., vol. 24, 1911, p. 54 (15 miles northeast of Chingningchow, Kansu, China).

Specimens.-Thirteen from Kansu: From the type locality, 12, including the type; and 45 miles northwest of Ninghsia, 1.

Not only are the ear and foot of this race distinctly longer than in Chihli specimens but the toes are heavier and longer. In regard to specimens which he kept in captivity, Sowerby found that they slept upon the side or back and if disturbed would kick and bite savagely. When not on the alert they had a queer habit of drooping the terminal half of the ears. Efforts to trap them proved unsuccessful, probably because no bait could be found to tempt them. The natives secured them by digging them out of their holes, "but," says Sowerby, "it takes a native to find the hole." They are called by the suggestive native name tiao-tu-tze, which means "jumping rump."

\section{Genus EUCHOREUTES Sclater}

\section{EUChOREUtes Naso alashanicus A. B. Howell}

Euchoreutes naso alashanicus A. B. Howell, Proc. Biol. Soc. Wash., vol. 41, 1928, p. 42 (Alashan Desert, Inner Mongolia, 100 miles north-northwest of Ninghsia, Kansu, China).

Specimen.-One, the type.

This is an ochraceous and pale race, with larger bullae.

\section{Genus DIPUS Zimmermann}

\section{DIPUS SOWERBYI Thomas}

Dipus sowerbyi Thomas, Ann. Mag. Nat. Hist., ser. 8, vol. 2, 1908, p. 307 (Yulinfu, Shensi, China).

Specimens.-Nine from Shensi: Yulinfu, 7 ; and 13 and 15 miles north of Yulinfu, 2.

Sowerby found these jerboas capable of making enormous leaps and one jumped out of a water jar three feet deep. Some which he kept in captivity slept during the day, usually lying on their sides, and so soundly did they sleep that one could pick them up and handle them without arousing them. Several times when in this condition they were thought to be dead. They are very frugal eaters, merely nibbling at vegetables or grain. They hibernate during the cold weather. 


\section{Family HYSTRICIDAE}

\section{Genus ACANTHION F. Cuvier}

ACANTHION SUBCRISTATUS (Swinhoe)

Hystrix subcristata Swinhoe, Proc. Zool. Soc. London, 1870, p. 638.

Specimen.-One from Suifu, Szechwan.

This specimen, the only Chinese porcupine in the National collection, is a juvenile, with flat skin and broken skull, but on the strength of the relatively long nasals, which extend much farther back than opposite the anterior border of the orbit, I venture to class it with the species of eastern China, rather than with yunnannensis.

\section{Order LAGOMORPHA}

\section{Family OCHOTONIDAE \\ Genus OCHOTONA Link \\ OCHOTONA (OCHOTONA) DAUURICA DAUURICA (Pallas)}

Lepus dauuricus Pallas, Reise, vol. 3, 1776, p. 692 (Mongolia).

Specimens.-Eight from Tabul, Chihli.

This series, in summer pelage, is of very uniform coloration.

\section{OCHOTONA (OCHOTONA) DAUURICA ANNECTENS Miller}

Ochotona annectens Mrller, Proc. Biol. Soc. Wash,, vol. 24, 1911, p. 54 (Chingningchow, Kansu, China).

Specimens.-Seven from Kansu: 15 miles northeast of Chingningchow, 6, including the type; 116 miles east of Lanchow, 1 .

As compared with available bedfordi the skull differences of annectens are too slight to be of great value in diagnosis. The body, and especially the hind feet, of the latter are the smaller, however, and the coloration is a faint shade darker. Where the above specimen was secured east of Lanchow, Sowerby found that the animals had their burrows in the (presumably rather bare) sides of the small gullies in loess gulches.

\section{OCHOTONA (OCHOTONA) DAUURICA BEDFORDI Thomas}

Ochotona bedfordi Thomas, Abst. Proc. Zool. Soc. London, 1908, p. 45 (Ningwufu, Shansi, China).

Specimens.-Seven: Wutsai, 3, and 30 to 50 miles northwest of Taiyuanfu, Shansi, 3; and 12 miles south of Yenanfu, Shensi, 1.

These are in full winter pelage, being in color very similar to daurica typicus but paler. The one from near Yenanfu is grayer. Sowerby found the burrows usually in very dense scrub where the sharp-thorned wild jujube afforded protection from enemies. 


\section{OCHOTONA (OCHOTONA) HUANGENSIS (Matschie)}

Conothoa huangensis Matschie, Wissens. Erg. Exped. Filchner China und Tibet, vol. 10, pt. 1, 1908, p. 214 (between Sianfu and Lanchow, Kansu, China).

Specimen.-One from 30 miles west of Sining, Kansu.

From the description of this race one infers that it is a member of the daurica group. The above specimen is comparable to this in color, and the bullae are about the same size but larger than in bedfordi, as Matschie said. The pelage, however, is of an entirely different quality, being relatively short and very woolly-not coarse as in daurica and its allies. The skull, too, is considerably more arched and the interorbital ridging is sharp and pinched in. The claws are entirely black and very long, although the latter feature may, of course, be due to local conditions.

\section{OCHOTONA (OCHOTONA) ERYTHROTIS VULPINA A. B. Howell}

Ochotona (Ochotona) erythrotis vulpina A. B. Howell, Proc. Biol. Soc. Wash., vol. 41, 1928, p. 117 (30 miles west of Sining, Kansu, China).

Specimens.-Three; the type and two topotypes.

Apparently this is the only Chinese subspecies of true erythrotis, having a summer coat that is of an intense reddish hue and with hairs entirely lacking black tips. It is of interest that this new race and a specimen of huangensis were secured in the same locality.

\section{OCHOTONA (OCHOTONA) GLOVERI Thomas}

Ochotona gloveri Thomas, Ann. Mag. Nat. Hist., ser. 9, vol. 9, 1922, p. 190 (Nagchuka, Szechwan, China).

Specimen.-One from the type locality.

In addition to the cinnamon ears, this August topotype has the nose of the same color. The relationship of this form to the species erythrotis can be considered as no nearer than specific.

\section{OCHOTONA (OCHOTONA) CHINENSIS Thomas}

Ochotona (Ochotona) chinensis Thomas, Ann. Mag. Nat. Hist., ser. 8, vol. 8, 1911, p. 728 (Yaratsaga, near Tatsienlu, Szechwan, China).

Specimens.-Four from Szechwan: Sungpan, 1; Ulongkong (10 miles south of Tatsienlu), 1; and Nganyangba, about 60 miles west of Tatsienlu, 2.

These specimens, differ from gloveri, which is probably their nearest relative, in being grayer and much darker because of more extensive black tipping of the hairs. The Sungpan individual is paler with more numerous whitish hairs, but can be called nothing else at present. 


\section{oChOtona (PIKA) AlPina ARgentata A. B. Howell}

Ochotona (Pika) alpina argentata A. B. Howell, Proc. Biol. Soc. Wash., vol. 41, 1928, p. 116 (15 miles north-northwest of Ninghsia, northern Kansu, China).

Specimens.-Two; the type and a tototype.

The array of Chinese pikas that have been described, and especially from Kansu, is quite formidable. Nevertheless it has been nècessary to name this race as the Chinese representative of alpina. In summer pelage it is of a striking shade of silvery with pale ochraceous rump.

\section{OCHOTONA (PIKA) SORELLA Thomas}

Ochotona sorella Thомаs, Abst. Proc. Zool. Soc. London, 1908, p. 45 (20 miles south of Ningwufu, Shansi, China).

Specimen.-One from 50 miles north of Taiyuanfu, Shansi.

This example comes from close to the type locality of sorella and it can hardly be doubted that this identification is correct. Its small, slender skull places it in relationship with $O$. cansa, as stated by Thomas, and the dimensions are even smaller (foot $25 \mathrm{~mm}$.) than of the type of sorella. Perhaps the fact that this is a midwinter specimen while the type was secured in summer explains the difference in coloration. At any rate the skin at hand is a miniature replica of a specimen of bedfordi from the same place, save that the soles of the feet are sooty. Othewise the coloration is identical; but of course the skull is subgenerically different. It is said to be an inhabitant of woods and Sowerby found it to be an extremely rare animal.

\section{OCHOTONA (PIKA) THIBETANA (Milne-Edwards)}

Lagomys thibetanus Milne-Edwards, Nouv. Arch. Mus., vol. 7, 1871, p. 93 (Muping, Szechwan, China).

Specimens.-Nine from Szechwan: Sungpan, 4; Washan, 2; and Ulongkong, 10 miles south of Tatsienlu, 3 .

The identification of these specimens is largely circumstantial. They are all very poorly made skins of juveniles with fragmentary skulls, but the coloration and palatal foramina of the three in which this part of the skull is intact show at least that they belong to this group. It is interesting to note that both this form and chinensis occur at Ulongkong.

\section{OCHOTONA (PIKA) CANSA MOROSA Thomas}

Ochotona cansus Lyon, Smiths. Misc. Colls., vol. 50, 1907, p. 136 (Taochow, Kansu, China).

Specimens.-Nine, including the type, from Taochow, Kansu.

These are June specimens in which there is considerable variation in tone of pelage because of differences in wear. 


\section{OCHOTONA (PIKA) CANSA MOROSA Thomas}

Ochotoha cansa morosa Thомаs, Ann. Mag. Nat. Hist., ser. 8, vol. 10, 1912, p. 403 (Taipeishan, Shensi, China).

Specimens.-Four skulls from the type locality.

The skins to the above skulls can not at present be located but I have no hesitation in their identification for they are very similar indeed to cansa typicus and from the type locality of morosa. Two of the skulls are larger than the measurements given by Thomas.

\section{Family LEPORIDAE}

\section{Genus CAPROLAGUS Blyth}

\section{CAPROLAGUS SINENSIS SINENSIS (Gray)}

Lepus sinensis GraY, Hardwicke's Illust. Indian Zool., vol. 2, 1833-34, pl. 20 (Canton, Kwangtung, China).

Specimens.-Seven from Kiangsu: Shanghai, 6, and Chinkiang, 1.

The Shanghai skins are very uniform but the one from Chinkiang is a bit darker and lacks any suggestion of gray upon the cheeks and about the base of the ears. I follow G. M. Allen (1927) in the generic disposition of this species.

\section{CAPROLAGUS SINENSIS FLAVIVENTRIS G. M. Allen}

Caprolagus sinensis faviventris G. M. Allen, Amer. Mus. Nov., No. 284, 1927, p. 5 (Chunganhsien, Fukien, China).

\section{Specimens.-Three from Yohow, Hunan.}

These skins have the underparts a bit more ochraceous and buffy than those from Shanghai, but the difference is very slight.

\section{Genus LEPUS Linnaeus \\ LEPUS TOLAI tolai Pallas}

Lepus tolai Pallas, Nov. Spec. Quad. Glir. Ord., 1778, p. 17 (Gobi Desert, Mongolia).

Specimens.-Twelve: Mongolia, 100 miles north of Kalgan, Chihli, 1; Paotowchen and 93 and 107 miles west-northwest thereof, Inner Mongolia, 6; Sianfu, Shensi, 1; and 85 miles north of Lanchow, 2, and west of Sining, Kansu, 2.

The skins from north of Kalgan seem perfectly typical of the race tolai. Although unexpected, I have no choice but to include the Sianfu individual under this name. The material from Inner Mongolia is in very ragged, dirty, late winter pesage, paler and less yellow than summer skins. The specimens from Kansu are in even worse condition as to pelage. The validity of the races gobicus and ganswicus Satunin remains to be established but it is doubted that they will prove distinct. 


\section{LEPUS TOLAI SUBLUTEUS Thomas}

Lepus swinhoei subluteus Thomas, Abst. Proc. Zool. Soc. London, 1908, p. 45 (Southern Ordos Desert, Mongolia).

Specimens.-Four: 20 miles west of Ningwufu, Shansi, 2 (including the type of $L$. sowerbyae); and 12 miles south of Yenanfu, Shensi, 2.

Thomas (1908) was correct in stating that hares indistinguishable from swinhoei range west across southern Shansi and Shensi, while subluteus occurs over the northern parts of these provinces. Hollister assumed one of the dark-chested examples of the former to be subluteus during comparisons of the specimen which he described under the name sowerbyae. The type of the latter and a topotype, however, are indistinguishable from typical subluteus and the name must be placed in the synonymy of the latter. Sowerby found this hare to be common in mountainous and hilly country as well as on the plains.

\section{LEPUS TOLAI SWINHOEI Thomas}

Lepus swinhoei Thomas, Ann. Mag. Nat. Hist., ser. 6, vol. 13, 1894, p. 364 (Chefoo, Shantung, China).

Specimens.-Four: Tientsin, 1, and 65 miles northeast of Peking, Chihli, 2 ; and 80 miles west-southwest of Sianfu, Shensi, 1.

One of the specinxans from northeast of Peking is a juvenile and considerably darker than the others. On the basis of the present material I can not recognize filchneri as a valid race.

\section{LEPUS TOLAI AURIGINEUS Hollister}

Lepus aurigineus Hollister, Proc. Biol. Soc. Wash., vol. 25, 1912, p. 181 (probably Kiukiang, Kiangsi, China).

Specimens.-Six: Kiukiang, Kiangsi, 1 (the type); Shanghai, Kiangsu, 1; and Suifu, Szechwan, 4.

This race was based upon a subadult, imperfect skin having so much of the tail missing that the color of this member can not be told. The label bears merely the word China, but the museum catalogue gives the information that the locality was Chiu Keang, which may or may not be Kiukiang, Kiangsi, and the date of capture December 27, 1880. There is also in the national collection a companion skin of the identical poor make and with a similar label, being indistinguishable from the type save that the entire tail is present. The position of this specimen in the accession catalogue is upon the line preceding the one occupied by the type of aurigineus. The locality is given as Shanghai (as it is upon the label), and the dat? of capture (not of accession) also December 27, 1880. Whether or not these two specimens were actually killed upon the samê day in the province of Kiangsi or of Kiangsu, they are most certainly of 
the same subspecies and identical in every respect. The upper surface of the tail of the Shanghai skin is black, which definitely places both with the species tolai, and the character of pelage, length of foot, and black ear markings corroborates the relationship. The anterior part of the nasals of the type has been broken off, which obviates the value of any observations upon this feature of the skull. The chief character of differentiation is the more ochraceous coloration, as already mentioned by G. M. Allen (1927).

The affinity of the Suifu specimens are with this race, although the two skins in good pelage are sufficiently darker to indicate that they may be subspecifically distinct; but these are flat skins without skulls. The soles of the feet are a veritable bright red, which may be a stain.

\section{LEPUS TOLAI MANDSHURICUS Radde}

Lepus mandshuricus RAdDE, Reise Suden Ost-Sibirien, 1862, p. 215 (BurejaGebirge (Mountains), eastern Siberia).

Specimen.-One from near Imienpo, Manchuria.

This race is much darker than tolai typious because of the greater number of black guard hairs. The suggestion of pink in the pelage is very characteristic.

\section{LEPUS GRAHAMI A. B. Howell}

Lepus grahami A. B. Howelt, Proc. Biol. Soc. Wash., vol. 41, 1928, p. 143 (Ulongkong, south of Tatsienlu, Szechwan, China).

Specimens.-Ten from Szechwan: five from the type locality and its vicinity, and five from near Sungpan.

This large, dark, slaty, mountain hare is very striking but is doubtless subspecifically related to $L$. comus.

\section{Order ARTIODACTYLA}

\section{Family SUIDAE}

\section{Genus SUS Linnaeus}

In the classification of the Chinese pigs I follow Sowerby. ${ }^{3}$ For his study he had a far greater number of skulls than skins, while in the present representation there is a preponderance of skins.

\section{SUS MOUPINENSIS Milne-Edwards}

Sus moupinensis Milne-Edwards, Nouv. Arch. Mus., vol. 7, 1871, p. 93 (Muping, Szechwan, China).

Specimens.-Seven: Yenanfu, 1, and 100 miles northwest of Sianfu, Shensi, 1; 20 miles west of Ningwufu, 1, 50 miles west of Fenchowfu, 1 , and 50 miles northwest of Taiyuanfu, Shansi, 3.

${ }^{3}$ Proc. Zool. Soc. London, 1917, p. 7. 
Sowerby has indicated that the Shansi pigs may be distinct from those of Shensi. Unfortunately the above Shensi specimens consist of a young pig, and an old boar in the excessively short, worn, pale coat sometimes met with and is useless for color comparison. Of the remaining material four are pigs of good size in splendid coat, which is distinctly paler than in Sus paludosus.

\section{SUS PALUDOSUS Heude}

$S[u s]$ paludosus Heude, Mems. Hist. Nat. Emp. Chinois, vol. 3, 1896, p. 193 (Kiangyin River at Nanking, Kiangsu, China).

Specimens.-Six: Yochow, Hunan, 2; near Chinkiang, Kiangsu, 1; Ningpo district, Chekiang, 2; and Peiliang, Fukien, 1.

The specimen from Kiangsu is a virtual topotype and is an adult female. The Yochow examples are immature and are not quite so red as the two specimens, of similar age, from the Ningpo district. The status of Sus meles is uncertain, as it is known only by a single skull with dentition that is probably not normal.

\section{SUS GIGAS Heude}

Sus gigas Heude, Mems. Hist. Nat. Emp. Chinois, vol. 2, 1892, p. 87 (Vladivostok, Siberia).

Specimen.-One from Imienpo, Manchuria.

This specimen is an exceedingly large sow in good coat which is slightly darker than in paludosus, but much darker than in moupinensis.

\section{Family CERVIDAE}

\section{Genus MOSCHUS Linnaeus}

\section{MOSCHUS SIFANICUS Büchner}

Moschus sifanicus Büchner, Mél. Biol. Acad. St. Petersb., vol. 12, 1890, p. 162 (southern Kansu, China).

Specimens.-Seven: Taochow, 2, and Archuen, Minshan Mountains, Kansu, 4; and Taipeishan, Shensi, 1.

It is not unlikely that the type of this species came from somewhere in the neighborhood of the Minshan Mountains. Five of the above skins are fairly uniform except for the coloration of the ears. The skin from Shensi and one of those from Archuen, however, are considerably different, being darker and with paler, better defined neck stripes, and with rump and hind legs almost black. Without a better understanding of the normal variation within the musk deer of China than the present material permits, their separation would be unjustified.

\section{MOSCHUS PARVIPES Hollister}

Moschus parvipes Hollister, Proc. Biol. Soc. Wash., vol. 24, 1911, p. 1 (below Mokpo, Korea).

Specimen.-One-the type. 


\section{Genus MUNTIACUS Rafinesque}

It seems extremely likely that Lydekker (1915) recognized a greater number of races of muntjac than warrantabie, and the material at my disposal leads me to believe that there are not two distinct species (reevesii and lachrymans) occupying the same districts over much of south China. The final question of the proper nomenclature to employ must, however, be left to someone having access to a large collection.

\section{MUNTIACUS REEVESII REEVESII (Ogilby)}

Cervus reevesii Ogmby, Proc. Zooi. Soc. London, 1838, p. 105 (Canton, Kwangtung, China).

Specimens.-Five: Yochow, Hunan, 2; Futsing, Fukien, 2; and Chekiang, 1.

Lydekker (1915) lists races of two species-M. lacrymans sctateri and $M$. reevesii reevesii - from both Foochow and Ningpo. These are differentiated by characters which I do not consider altogether reliable, some of them probably varying with the individual and others with age, and even sex. The male and female from Fukien match one of these forms in certain respects, and the second in still others. The prior specific name-reevesii-is therefore used for all three individuals. Their skulls do not differ in any important characters: the nasals of all are expanded caudad of the maxillary juncture, and the lachrymal pits proper, slightly smaller than the orbits, do not quite occupy the whole lachrymal bone. The horns of the adult male project but $15 \mathrm{~mm}$. beyond the integument. In both Fukien skins, taken on March 8 and 9, the dorsal color is the same shade of bright reddish ochraceous, the female being grayer on the sides. The latter has a narrow nuchal stripe, black forehead and dusky ears. The male has a yellow forehead and ears and practically no nuchal stripe. All of these points, possibly with the exception of ear color, are usual sexual differences of this genus. Both examples have pale buffy throats. The Ningpo skin is of a female taken in January and is much darker and duller, with darker throat, brown ears, and extensive dark forehead area. The latter differences may be subspecific and not largely ascribable to seasonal variation, but evidently no existing name may be used for it unless it be one of the above, and it is thought better for the present to assign all three to the same race. The Hunan skins are very similar.

\section{MUNTIACUS REEVESII LACHRYMANS (Milne-Edwards)}

Cervulus lachrymans Mrlne-Edwards, Arch. Mus. Paris, vol. 7, 1871, p. 93 (Muping, Szechwan, China).

Specimens.-Eleven from Szechwan; Suifu, 4; Mount Omei, 6; and Washan, 1. 
Szechwan specimens of muntjac in good coat are considerably brighter than the two individuals of the race sclateri, and the brighter parts of the head markings are more reddish. From typical reevesii they differ very slightly, the most trustworthy detail apparently being the greater broadness of the black superciliary marks in the males; and the legs also average a bit darker. I can distinguish no skull differences in this material and, in fact, consider the race a poor one; but it may be recognized under this name largely for the sake of expediency.

\section{MUNTIACUS REEVESII SCLATERI (Swinhoe)}

Cervulus solateri Swinhoz, Proc. Zool. Soc. London, 1872, p. 814 (Ningpo, Chekiang, China).

Specimens.--Two from Kiangsu; Soochow, 1, and Chekiang, 1.

These specimens are readily separable from true reevesii, as I understand the latter, and the above name is the one that should be used for them. They are without date so the difference in body color may possibly be seasonal; but at any rate the coat is considerably duller and browner (less red), and the brighter part of the forehead of the male is paler than in any comparable reevesii. The base of the rostrum is also relatively broader, so that the outline from the premaxillae to the zygomatic arches is almost straight, instead of much curved as in every other skull of the genus available.

\section{Genus ELAPHODUS Milne-Edwards}

ELAPHODUS CEPHALOPHUS Milne-Edwards

Elaphodus cephalophus Milne-Edwards, Arch. Mus, Paris, vol. 7, 1871, p. 93 (Muping, Szechwan, China).

Specimens.-Three from Szechwan; Wenchwan, 2, and Mount Omei, 1.

\section{Genus CERVUS Linnaeus}

CERVUS (SIKA) MANTCHURICUS Swinhoe

Cervus mantchuricus SwINHoE, Proc. Z Zol. Soc. London, 1864, p. 169 (Man(churia).

Specimens.-Three from Korea.

The coloration of the metatarsal glands is not constant in this group but varies, perhaps, with age or season.

CERVUS KANSUENSIS Pocock

Cervus kansuensis Pocock, Proc. Zool. Soc. London, 1912, p. 573 (30 miles southeast of Taochow, Kansu, China).

Specimens.-Twelve: near Taochow, Kansu, 6; and west of Kueihuacheng, Shansi, 6. 
I am not in a position to form an opinion in regard to the validity of this race of stag. There is a good deal of uniformity in the body color in respect to season, but considerable variation in the nuchal stripe and in rump marking. In animals from the same locality the black of the upper rump may extend to the tail tip, or again the whole of the lower rump above the tail may be whitish, or of an intermediate character.

\section{CERVUS XANTHOPYGUS Milne-Edwards}

Cervus xanthopygus Milne-Edwards, Ann. Sci. Nat. Paris, vol. 5, p. 8, 1869, p. 376 (probably the Ussuri district, Manchuria).

Specimens.-Three from Imienpo, Manchuria.

This form is very distinct from knsuensis, with a reddish tone which the latter lacks. An immature is as red as any Capreolus.

\section{Genus ELAPHURUS Milne-Edwards}

\section{ELAPHURUS DAVIDIANUS Milne-Edwards}

Elaphurus davidianus Milne-Edwards, Ann. Sci. Nat. Paris, vol. 5, pt. 5, 1866, p. 380 (Peking, Chihli, China).

The National collection contains a mounted specimen and skull without horns (possibly the same individual) from Woburn Abbey.

\section{Genus CAPREOLUS Gray \\ CAPREOLUS BEDFORDI Thomas}

Capreolus bedfordi Thomas, Abst. Proc. Zool. Soc. London, 1908, p. 32 (100 miles northwest of Taiyuanfu, Shansi, China).

Specimens.-Seven : 50 miles west of Fenchowfu, 2, and Kneihuacheng, Shansi, 1; 12 miles south of Yenanfu, Shensi, 2; Hsinlungshan, Chihli, 1; and a single specimen from an unknown locality.

The relationship of the different forms of Asiatic roe deer is imperfectly understood and for the present they may be treated as full species. None of these specimens exhibits any tendency toward the blackening of the ears that is characteristic of melanotis.

\section{CAPREOLUS MELANOTIS Miller}

Capreolus melanotis Miller, Proc. Biol. Soc. Wash., vol. 24, 1911, p. 231 (30 miles east of Chingyangfu, Kansu, China).

Specimen.-One-the type.

\section{CAPREDLUS PYGARGUS (Pallas)}

Cervus pygargus Pallas, Reise Russul., vol. 1, 1777, p. 97 (Altai, Siberia).

Specimen.-One from Imienpo, Manchuria.

This September skin is still in the summer coat, which is of the brown type and rather dark-not the red type characteristic of 
the two previous forms. It is probably not typical but seems to be nearer pygargus than anything else that has been described.

\section{Genus HYDROPOTES Swinhoe \\ HYDROPOTES INERMIS INERMIS Swinhoe}

Hydropotes inermis Swinhoe, Proc. Zool. Soc. London, 1870, p. 89 (Chinkiang, Kiangsu, China).

Specimens.-Thirteen: Yochow, Hunan, 10; Anhwei, 1; Soochow, 1, and Chinkiang, Kiangsu, 1.

This fine series shows that there is much individual variation in color, and in size of skull, within this genus.

\section{HYDROPOTES INERMIS ARGYROPUS Hilzheimer}

Hyrdopotes argyropus Hizheimer, Abhand. Mus. Naturk., Madgeburg, vol. 1, 1906, p. 171 (Korea).

Specimens.-Eleven: from Korea, 5 odd skulls and 4 odd skins, and 2 from north China or Manchuria.

Heude was the originator of this racial name but his use of it constituted a nomen nudum and Hilzheimer seems to be the one who should be credited with its acceptable use. The form is recognized on the basis of average darker and richer coloration, with more reddish about the head. The skull exhibits no consistent differences. The disposal of the two skins from uncertain localities is a question, and they are allocated provisionally. They are in extremely heavy, pale, winter pelage and are very different from any of the others, which may be due entirely to season.

\section{Family BOVIDAE}

\section{Genus OVIS Linnaeus}

\section{OVIS AMMON AMMON (Linnaeus)}

Capra ammon Linnaeus, Syst. Nat., ed. 12, vol. 1, 1766, p. 97 (Upper Irtiseh River, Siberia).

Specimens.-Four, from near Tchegan-Burgazi Pass, Mongolia.

These skins were purchased in Kosh-Agatch. Two are in pale gray and very short summer coat and two in heavy winter pelage. One of these is rather light and the other very dark indeed, with a middorsal stripe that becomes perfectly white below the withers. I can hardly believe that these two are of the same subspecies but as one cannot be certain where they were secured they must both be placed under this race for the present. 
OVIS AMMON KOZLOVI Nasonov

Ovis kozlovi Nasonov, Bull. Acad. Imp. Sci. St. Petersb., 1913, p. 621 (Jabarai Mts., southern Gobi, Mongolia).

Specimens.-Five from Kueihuacheng, Shansi.

This race seems to be tenable, based chiefly on the dingy hue, rather than a pure white, of the rump patch. The summer pelage is unusually rusty.

\title{
Genus PSEUDOIS Hodgson
}

\author{
PSEUdOIS NAYAUR CAESIA A. B. Howeil
}

Pseudois nayaur caesia A. B. Howfll, Proc. Biol. Soc. Wash., vol. 41, 1928, p. 118 (Archuen, Minshan Range, Kansu, China).

Specimens.-Archuen, 1 (the type), and Ninghsia, Kansu, 4; and. 157 miles west-northwest of Paotowchen, Inner Mongolia, 3.

It was only to be expected that the bharal of Kansu would prove to be a separable race.

\section{Genus CAPRICORNIS Ogilby}

\section{CAPRICORNIS MILNE-EDWARDSI David}

Capricornis milne-edwardsi David, Arch. Mus. Paris, vol. 5, 1869, p. 10 (Muping, Szechwan, China).

Specimens.-Three: Tibetan border of Kansu, 2; and Washan, Szechwan, 1.

In the light of present knowledge it seems that all three of these specimens of serows must be listed under this name. The presence or absence of a black stripe upon the foreleg evidently means but little, for one Kansu individual has it and the other has not. The hairs of the rump of the Washan skin are tipped with black, a character which the others lack. It seems that the white hairs of the mane, which is not extensive in these pelts, are coarser and more brittle than the remainder of the pelage and that the tips are prone to breakage; hence the presence or absence of a mane is largely seasonal.

\section{Genus NAEMORHEDUS H. Smith}

\section{NAEMORHEDUS CAUDATUS (Milne-Edwards)}

[Antilope] caudata Milne-Edwards, Ann. Sci. Nat., ser. 5, vol. 7, 1867, p. 377 [Based on:-Antilope crispa Radde, 1862, Reisen im Süden von Ost-Sibirien, vol. 1, Die Säugethierfauna, St. Petersburg, p. 263 ; Amur].

Naemorhedus caudatus Milne-Edwards, Rech. Mamm., 1874, p. 361 (Mongolia).

Specimens.-Three: Kueihuacheng, Shansi, 1; Liutsuen, Shensi, 1; and Wenchwen, Szechwan, 1. 
These three pelts show such a mixture and intergradation of the characters that are usually assigned to caudatus and to griseus that I must provisionally place them under the older name.

\section{NAEMORHEDUS RADDEANUS (Heude)}

Kemas raddeanus Heude, Mem. Hist. Nat. Emp. Chinois, vol. 2, 1894, p. 240 (Ussuri, Manchuria).

Specimens.-Two from Imienpo, Manchuria.

These pelts are easily distinguished by the dirty whitish instead of black tail tip, the greater extent of black upon the fore legs, and by the heavier pelage. Greater size seems also indicated.

\section{Genus BUDORCAS Hodgson}

\section{BUDORCAS TIBETANUS Milne-Edwards}

Budorcas taxicolor var. tibetanus Milne-Edwards, Rech. Mamm., 1874, p. 367 (Muping, Szechwan, China).

Specimens.-One mounted example from Tatsienlu, Szechwan.

\section{BUDORCAS BEDFORDI Thomas}

Budorcas bedfordi Thomas, Abst. Proc. Zool. Soc. London, 1911, p. 27 (Taipeishan, Shensi, China).

Specimen.-One from Taipeishan district, Shensi.

This topotype seems to be an exact match for the figure given by 'Thomas.

\section{Genus GAZELLA Lichtenstein}

\section{GAZELLA PRZEWALSKII Büchner}

Gazella przewalskii Büchner, Mél. Biol. Acad. Sci. St. Petersb., vol. 13, 1890, p. 161 (Mongolia).

Specimens.-Four : 80 miles south-southwest of Ninghsia, Kansu; and 157 miles west-northwest of Paotowchen, Inner Mongolia.

Skins of this species are readily distinguished from those of $G$. gutturosa chiefly by the longer black tail, tufted forelegs, much duller color, and differences in facial markings. Two are in summer and two in winter coat.

\section{GAZELla GUTTURosa (Pallas)}

Antilope gutturosa Pallas, Spicil. Zool., vol. 12, 1777, p. 46 (Mongolia).

Specimens.-Seven from the vicinity of Tabul, Chihli.

These are in summer coat and the bright coloration is very uniform. 


\section{Order EDENTATA}

\section{Family MANIDAE \\ Genus MANIS Linnaeus \\ MANIS DALMANNI Sundevall}

Manis dalmanni Sundevall, Vetense. Akad. Handl., 1842, p. 256 (Canton, Kwangtung, China).

\section{Specimen.-One from Foochow, Fukien.}

The Chinese members of this genus are in need of revision. Pocock (1924) has cleared up generic questions, but the literature seems to offer little to elucidate the relationships of dalmanni, aurita, and pentadactyla. The above skin, however, matches the descriptions of the first-mentioned form and not the others. Longitudinal rows of scales number 15, and there are 19 keeled scales upon the border of the tail.

\section{MANIS AURITA Hodgson}

Manis aurita Hodgson, Journ. Asiatic Soc. Bengal, vol. 5, 1836, p. 234.

Specimen.-One from Yunnan, bought between Tengyueh and Yunlung, undoubtedly from either the Salween or Mekong river valley.

This dried specimen has a present total length of $470 \mathrm{~mm}$. The claws are of the same color as the scales, the latter are not keeled on the flanks and are arrayed in 15 rows over the back, while the keeled scales of the tail border number 17 .

\section{Order CETACEA}

\section{Family ODONTOCETI}

\section{Genus LIPOTES Miller}

LIPOTES VEXILLIFER Miller

Lipotes vexillifer MrLler, Smiths. Misc. Coll., vol. 68, 1918, p. 8 (Tungting Lake, Hunan, China).

Specimen.-One-the type.

\section{Genus NEOMERIS Gray \\ NEOMERIS PHOCAENOIDES (Cuvier)}

Delphinus phocaenoides Cuvier, Reg. Anim., 1829, p. 291.

Specimens.-Eight from Kiangsu: one skin and skeleton from Whangpu River; one in spirits from Whangpu Creek; another from the Yangtze River; and three more in spirits and two skeletons from Woosung. In addition, the skeleton has been removed from one of the last mentioned individuals.

These specimens have been discussed elsewhere. ${ }^{4}$

‘ Howell, Proc. U. S. Nat. Mus., vol. 70, 1927, art. 13, pp. 1-43. $21776-29-6$ 


\section{EXPLANATION OF PLATES}

\section{Plate 1}

\section{Frontispiece}

Map showing the provinces of China, after the atlas of the China Inland Mission.

\section{Plate 2}

$a$, Crocidura grisea, type; $b$, Crocidura dracula griscescens, type; $c$, Hipposideros armiger swinhoii; $d$, Hipposideros pratti; $e$, Coelops robinsoni; $f$, Coelops inflatus, type; $g$, Myotis hirsutus, type; $h$, Myotis soverbyi, type; all natural size.

\section{Plate 3}

$a, a^{1}$, Ochotona (Ochotona) erythrotis vulpina, type; $b, b^{1}$, Ochotona (Pika) alpina argentata, type; both natural size; $c$, Lepus tolai subluteus; $d$, Lepus grahami, type; both slightly reduced.

\section{Plate 4}

$a, a^{1}$, Petaurista sulcatus, type, natural size; $b$, Pseudois nayaur caesia, type, greatly reduced.

\section{Plate 5}

Pithecus pullus, type, one-half natural size.

Plate 6

Dorsal aspect of the skull of the type of Selenarctos thibetanus wulsini, onehalf natural size.

\section{Plate 7}

Palatal aspect of the skull of the type of Selenarctos thibetanus wulsini, onehalf natural size.

\section{Plate 8}

Dorsal aspect of the skull of an adult Ursus cavifrons, two-fifths natural size.

\section{Plate 9}

Palatal aspect of the skull of an adult Ursus cavifrons, two-fifths natural size.

\section{Plate 10}

Palatal aspect of the skull of a juvenal Ursus leuconyx, one-half natural size. 


\section{$2 \mathrm{BHL}$ Biodiversity Heritage Library}

Howell, A. Brazier. 1929. "Mammals from China in the collections of the United States National Museum." Proceedings of the United States National Museum 75(2772), 1-82. https://doi.org/10.5479/si.00963801.75-2772.1.

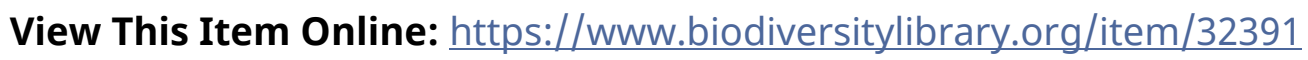

DOI: https://doi.org/10.5479/si.00963801.75-2772.1

Permalink: https://www.biodiversitylibrary.org/partpdf/7794

\section{Holding Institution}

Smithsonian Libraries

\section{Sponsored by}

Smithsonian

\section{Copyright \& Reuse}

Copyright Status: NOT_IN_COPYRIGHT

Rights: https://www.biodiversitylibrary.org/permissions/

This document was created from content at the Biodiversity Heritage Library, the world's largest open access digital library for biodiversity literature and archives. Visit BHL at https://www.biodiversitylibrary.org. 